\title{
Function Synthesis of Bennett 6R Mechanisms Using Chebyshev Approximation
}

\author{
Rasim I. Alizade ${ }^{\mathrm{a}}$, Gökhan Kiper ${ }^{1, a}$, Barış Bağdadioğlu ${ }^{\mathrm{a}}$, M. İ. Can Dede ${ }^{\mathrm{a}}$ \\ ${ }^{a}$ Mechanical Engineering Department, İzmir Institute of Technology, 35430 İzmir, Turkey
}

\begin{abstract}
This study focuses on approximate function synthesis of the three types of overconstrained Bennett 6R mechanisms using Chebyshev approximation. The three mechanisms are the double-planar, double-spherical and the plano-spherical 6R linkages. The single-loop 6R mechanisms are dissected into two imaginary loops and function synthesis is performed for both loops. First, the link lengths are employed as construction parameters of the mechanism. Then extra construction parameters for the input or output joint variables are introduced in order to increase the design points and hence enhance the accuracy of approximation. The synthesis formulations are applied computationally as case studies. The case studies illustrate how a designer can compare the three types of Bennett 6R mechanisms for the same function. Also we present a comparison of the spherical four-bar with the double-spherical 6R mechanism and show that the accuracy is improved when the 6R linkage is used.
\end{abstract}

Keywords: Function synthesis, Bennett 6R mechanisms, method of decomposition, Chebyshev approximation

\section{Introduction}

When manufactured precisely, overconstrained mechanisms prove themselves to have higher precision compared to simply constrained mechanisms. The motivation of this study is to investigate the approximate synthesis of an overconstrained mechanism which belongs to subspace $\lambda=5$. A $\lambda=5$ mechanism means that the position and orientation of all links of the mechanism can be described with at most five independent parameters at any instant during the motion of the mechanism. Two obvious $\lambda$ = 5 subspaces are the RRRPP and RRPPP subspaces, for which a translational or rotational degree-offreedom (dof) is constrained.

The first example of a $\lambda=5$ mechanism is the Sarrus (1853) linkage. The Sarrus linkage is a spatial $6 \mathrm{R}$ linkage (a linkage with six revolute joints) obtained by assembling two planar dyads in perpendicular planes. Later, Bennett (1905) generalized the Sarrus linkage such that the angle between the planes of the dyads is arbitrary (Fig. 1a). For this linkage, no link has a rotational motion about the axis along the intersection of the planes of the dyads, so the linkage belongs to an RRPPP type of $\lambda=5$ subspace. The generalized Sarrus linkage can be considered as the combination of two planar slider-crank mechanisms in intersecting planes such that the fixed link and the slider link is common to both of the slider cranks. The sliding direction is along the intersection of the planes. In such an assembly, the linkage remains mobile with single dof even if the prismatic joint is removed. Hence a single loop, 6R linkage is obtained. The removed prismatic joint is defined as a passive joint (Selvi, 2012).

\footnotetext{
${ }^{1}$ Corresponding author. Tel.: +90 232 7506777; fax: +90 2327506701.

E-mail address: gokhankiper@iyte.edu.tr (G. Kiper).
} 

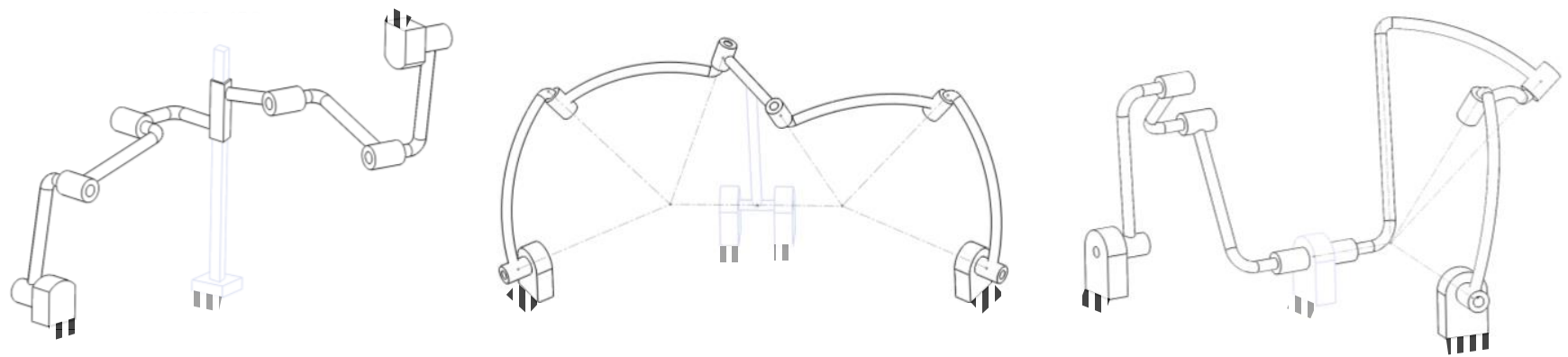

Fig. 1 a) Double-planar 6R (generalized Sarrus) linkage, (b) double-spherical 6R linkage, and (c) plano-spherical 6R linkage with their passive joints

Along with the generalized Sarrus linkage, Bennett (1905) introduced two more $\lambda=5$ mechanisms. One of these mechanisms is the double-spherical 6R mechanism which is obtained by merging two spherical four-bar linkages with two common links and then removing the joint connecting the common links. The removed revolute joint is the passive joint of this linkage and its axis is along the line connecting the centers of the spherical four-bars (Fig. 1b). It seems not possible to classify this linkage in an RRPPP or an RRRPP type of $\lambda=5$ subspace. The other mechanism is the plano-spherical $6 \mathrm{R}$ mechanism, which is obtained by merging a planar four-bar linkage and a spherical four-bar linkage with two common links. Once again, the revolute joint connecting the common links is removed to obtain the 6R linkage (Fig. 1c). The axis of this passive joint passes through the center of the spherical four-bar and it is in the same direction as all the axes of the planar four-bar. For this linkage, no link has a translational motion along the direction of axes of the planar four-bar, hence the linkage belongs to an RRRPP type of $\lambda=5$ subspace.

In this study, we investigate function synthesis of the double-planar (generalized Sarrus), the double spherical and the plano-spherical 6R linkages. Since these mechanisms have more construction parameters than simple single-loop mechanisms such as the planar four-bar, spherical four-bar and planar slider-crank mechanisms, we expect to attain more precise function synthesis.

The synthesis of the single-loop planar linkages is vastly studied (Erdman, Sandor, 1997). Synthesis of spherical four-bar mechanism (SFBM) is also widely studied. Hartenberg and Denavit (1964) and Zimmerman (1967) have respectively presented the three- and four-precision-point function generation of the SFBM. Cervantes- Sánchez et al. (2009a) have worked on formulation of the function synthesis problem of the SFBM for three and four precision points and further presented formulations for five and six precision points (Cervantes- Sánchez et al., 2009b). Rao et al. (1973), Farhang et al. (1988, 1999), Alizade et al. (1994, 2005) and Murray and McCarthy (1995) used polynomial approximation method for three, four and five precision points for the function synthesis of the SFBM. Suixian et al. (2009) worked on the optimal selection of precision points. Alizade and Gezgin (2011) have applied interpolation, least squares and Chebyshev approximation methods to solve the six-precision-point function synthesis of the SFBM. Maaroof and Dede $(2013,2014)$ have worked on the synthesis of the double-spherical 6R linkage using interpolation approximation.

Recently, Alizade et al. (2013) investigated the derivation of the input/output (I/O) relationships of the three types of Bennett 6R linkages using the method of decomposition (Alizade et. al, 1980). In this study, we shall use the I/O equations obtained in that paper.

In Section 2, we outline the Chebyshev approximation method for synthesis of mechanisms. In Section 3 , we derive the objective functions for the Bennett mechanisms and formulate equations necessary for the synthesis. In Section 4, we show how to relate the function to be generated to the mechanism joint 
parameters. In Section 5, we present some case studies and the discussions section concludes the article.

\section{Chebyshev Approximation}

In this section we review the polynomial approximation methods first studied by Chebyshev in $1850 \mathrm{~s}$ (Chebyshev, 1854, 1859). Let $\mathrm{f}(\mathrm{x})$ be a continuous function defined on $\mathrm{x} \in[\mathrm{a}, \mathrm{b}]$. A polynomial $\mathrm{P}_{\mathrm{n}}(\mathrm{x})$ of degree $n$ is called the best approximation of $f(x)$ if $L=\max |f(x)-P(x)|$ is minimum. The alternation theorem of Chebyshev states that for a given function $\mathrm{f}(\mathrm{x})$ and order $\mathrm{n}$ the best approximation is unique and the maxima $L$ are attained $n+2$ times on $[a, b]$ alternately with opposite signs. Although this theorem guaranties the unique existence of the best approximation of a function, neither it, nor its proof leads to a method to find the best approximation. An iterative method is proposed by Remez (1932). The Remez algorithm is as follows (Temes, 1967):

1. Select design points $x_{i}^{0} \in[a, b], i=0, . ., n+1$ (usually $x_{0}=a, x_{n+1}=b$ ) and linearly solve for the coefficients of an approximation polynomial $P_{n}^{0}(x)$ and $L$ from the $n+2$ equations $\mathrm{P}_{\mathrm{n}}^{0}\left(\mathrm{x}_{\mathrm{i}}{ }^{0}\right)-\mathrm{f}\left(\mathrm{x}_{\mathrm{i}}{ }^{0}\right)=(-1)^{\mathrm{i}} \mathrm{L}$

2. Find the $n+2$ local extrema $x_{i}^{1}$ of $E^{0}(x)=P_{n}{ }^{0}\left(x_{i}{ }^{0}\right)-f\left(x_{i}^{0}\right)$ in $[a, b]$.

3. Repeat steps 1 and 2 by replacing $x_{i}^{j}$ by $x_{i}{ }^{j+1}$ until the design points stabilize.

Convergence is not guaranteed in this iterative algorithm. In function synthesis of mechanisms, we derive the input/output $(\mathrm{I} / \mathrm{O})$ relationship which is a function of the construction parameters of the mechanism and input and output variables. The $\mathrm{I} / \mathrm{O}$ equation is written in a polynomial form $P_{n}(\mathbf{x})=\sum_{j=1}^{n} P_{j} f_{j}(\mathbf{x})$, called the objective function, where $P_{j}$ are functions of the construction parameters and $f_{j}$ are the functions of the input and output variables represented by $\mathbf{x}$. If the number of coefficients $\mathrm{P}_{\mathrm{j}}(=\mathrm{n})$ is equal to the number of construction parameters, then given $\mathrm{n}+1$ many design points $\left\{\mathbf{x}_{\mathrm{i}}\right\}_{1}^{\mathrm{n}+1}$, the coefficients $\left\{\mathrm{P}_{\mathrm{j}}\right\}_{1}^{\mathrm{n}}$ and the Chebyshev error L are linearly solved from

$$
\sum_{j=1}^{n} P_{j} f_{j}\left(\mathbf{x}_{i}\right)-F\left(\mathbf{x}_{i}\right)=(-1)^{i+1} L \text { for } \mathrm{i}=1, \ldots, n+1
$$

Once $\left\{\mathrm{P}_{\mathrm{j}}\right\}_{1}^{\mathrm{n}}$ are solved, the construction parameters are determined from $\left\{\mathrm{P}_{\mathrm{j}}\right\}_{1}^{\mathrm{n}}$. If the number of coefficients $P_{j}(=n)$ is greater than the number of construction parameters, it means that the coefficients $P_{j}$ are interrelated. For illustration, consider the case where there are $n-1$ construction parameters, but $P_{j}=n$. Then we choose a coefficient, say, $P_{n}$, which is expressible in terms of the others. Let $P_{n}=\lambda, P_{j}$ $=\ell_{j}+m_{j} \lambda$ for $j=1, \ldots, n-1$ and $L=\ell+m \lambda$. Eq. (1) can be reformulated as

$$
\sum_{j=1}^{n-1}\left(\ell_{j}+m_{j} \lambda\right) f_{j}\left(\mathbf{x}_{i}\right)+\lambda f_{n}\left(\mathbf{x}_{i}\right)-F\left(\mathbf{x}_{i}\right)=(-1)^{i+1}(\ell+m \lambda) \text { for } i=1, \ldots, n
$$

The multipliers of $\lambda$ may be collected in Eq. (2):

$$
\sum_{j=1}^{n-1} \ell_{j} f_{j}\left(\mathbf{x}_{i}\right)-F\left(\mathbf{x}_{i}\right)+\lambda\left[\sum_{j=1}^{n-1} m_{j} f_{j}\left(\mathbf{x}_{i}\right)+f_{n}\left(\mathbf{x}_{i}\right)\right]=(-1)^{i+1} \ell+\lambda(-1)^{i+1} m, i=1, \ldots, n
$$


Equating the coefficients of $\lambda$ and the remaining parts in Eq. (3) we obtain

$$
\sum_{\mathrm{j}=1}^{\mathrm{n}-1} \ell_{\mathrm{j}} \mathrm{f}_{\mathrm{j}}\left(\mathbf{x}_{\mathbf{i}}\right)+(-1)^{\mathrm{i}} \ell=\mathrm{F}\left(\mathbf{x}_{\mathbf{i}}\right) \text { and } \sum_{\mathrm{j}=1}^{\mathrm{n}-1} \mathrm{~m}_{\mathrm{j}} \mathrm{f}_{\mathrm{j}}\left(\mathbf{x}_{\mathbf{i}}\right)+(-1)^{\mathrm{i}} \mathrm{m}=-\mathrm{f}_{\mathrm{n}}\left(\mathbf{x}_{\mathbf{i}}\right), \mathrm{i}=1, \ldots, \mathrm{n}
$$

Eq. (4) is a set of $2 n$ linear equations with unknowns $\left\{\ell_{j}\right\}_{1}^{n-1},\left\{m_{j}\right\}_{1}^{n-1}, \ell$ and $m$. After the unknowns are determined, since there is a relationship between $\mathrm{P}_{n}=\lambda$ and some other coefficients, $\lambda$ is solved from this relationship. $P_{i}=\ell_{j}+m_{j} \lambda$ for $j=1, \ldots, n-1$ and $L=\ell+m \lambda$ are determined. The $n-1$ construction parameters are solved from $\left\{\mathrm{P}_{\mathrm{j}}\right\}_{1}^{\mathrm{n}-1}$.

If there are $n-2$ construction parameters for $P_{j}=n$, we let $P_{n-1}=\lambda_{1}, P_{n}=\lambda_{2}, P_{j}=\ell_{j}+m_{j} \lambda_{1}+n_{j} \lambda_{2}$ for $j=$ $1, \ldots, \mathrm{n}-2$ and $\mathrm{L}=\ell+\mathrm{m} \lambda_{1}+\mathrm{n} \lambda_{2} . \mathrm{P}_{\mathrm{n}-1}$ and $\mathrm{P}_{\mathrm{n}}$ should be dependent on other coefficients. Eq. (1) becomes

$$
\sum_{j=1}^{n-2}\left(\ell_{j}+m_{j} \lambda_{1}+n_{j} \lambda_{2}\right) f_{j}\left(\mathbf{x}_{i}\right)+\lambda_{1} f_{n-1}\left(\mathbf{x}_{i}\right)+\lambda_{2} f_{n}\left(\mathbf{x}_{i}\right)-F\left(\mathbf{x}_{i}\right)=(-1)^{i+1}\left(\ell+m \lambda_{1}+n \lambda_{2}\right) \text { for } \mathrm{i}=1, \ldots, n-1
$$

Equating the coefficients of $\lambda_{1}, \lambda_{2}$ and the remaining parts in Eq. (5) we obtain

$$
\sum_{j=1}^{n-2} \ell_{j} f_{j}\left(\mathbf{x}_{i}\right)+(-1)^{i} \ell=F\left(\mathbf{x}_{i}\right), \sum_{j=1}^{n-2} m_{j} f_{j}\left(\mathbf{x}_{i}\right)+(-1)^{i} m=-f_{n-1}\left(\mathbf{x}_{i}\right) \text { and } \sum_{j=1}^{n-2} n_{j} f_{j}\left(\mathbf{x}_{i}\right)+(-1)^{i} n=-f_{n}\left(\mathbf{x}_{i}\right), i=1, \ldots, n-1(6)
$$

$\left\{\ell_{\mathrm{j}}\right\}_{1}^{\mathrm{n}-2},\left\{\mathrm{~m}_{\mathrm{j}}\right\}_{1}^{\mathrm{n}-2},\left\{\mathrm{n}_{\mathrm{j}}\right\}_{1}^{\mathrm{n}-2}, \ell, \mathrm{m}$ and $\mathrm{n}$ are solved linearly from Eq. (6). Then $\lambda_{1}$ and $\lambda_{2}$ are solved from the relationship in between $P_{n-1}, P_{n}$ and the other coefficients. $P_{j}=\ell_{j}+m_{j} \lambda_{1}+n_{j} \lambda_{2}$ for $j=1, \ldots, n-2$ and $\mathrm{L}=\ell+\mathrm{m} \lambda_{1}+\mathrm{n} \lambda_{2}$ are determined. The $\mathrm{n}-2$ construction parameters are solved from $\left\{\mathrm{P}_{\mathrm{j}}\right\}_{1}^{\mathrm{n}-1}$.

\section{The Objective Functions}

The I/O relationships of the Bennett 6R mechanisms are derived in (Alizade et al., 2013). We shall formulate the objective functions based on the I/O relationships.

\subsection{The Double-Planar 6R Mechanism with 6 Parameters}

Together with the passive prismatic joint, the double-planar 6R linkage may be considered to be composed of a pair of slider-crank mechanisms. Let $\phi$ be the input angle, $\theta$ be the output angle and $\mathrm{s}$ be the passive joint variable of the double-planar 6R mechanism shown in Fig. 2. For the time being, assume $\phi_{0}, \mathrm{~s}_{0}$ and $\theta_{0}$ to be zero. The relationship between the input $\phi$ and the output $\theta$ does not change if the mechanism dimensions are scaled, so without loss of generality we may assume the fixed link length $\mathrm{g}=1$. 


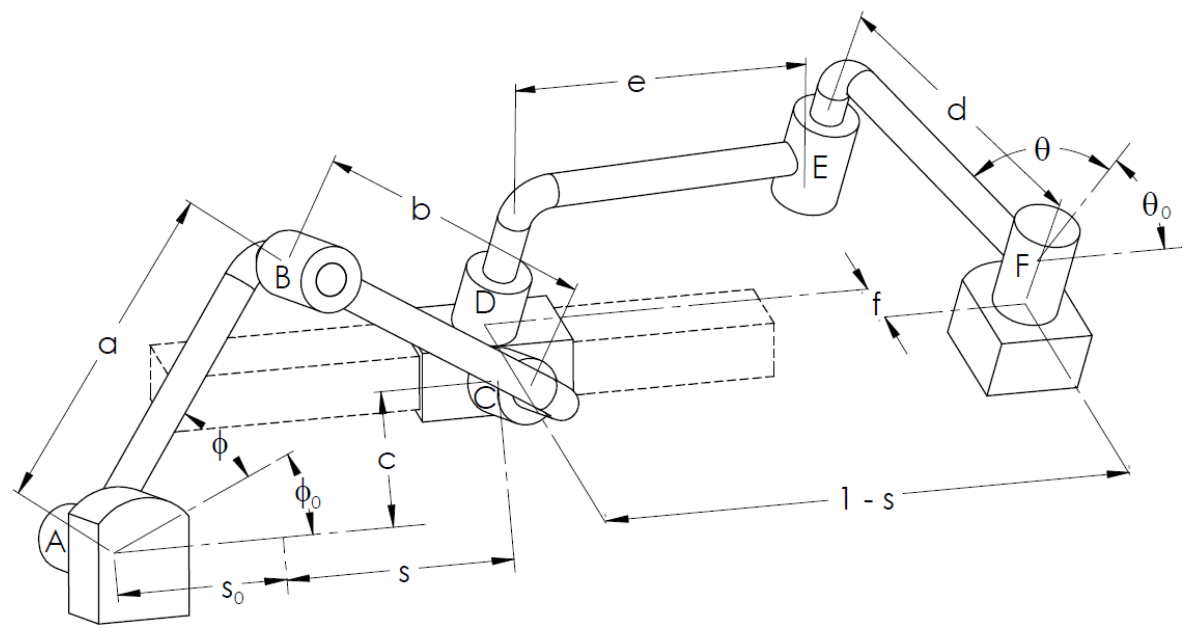

Fig. 2 Kinematic representation of the double-planar 6R linkage

For the double planar 6R mechanism the I/O equation for the imaginary loop ABC is given by (Alizade et al., 2013)

$$
\mathrm{b}^{2}=(\mathrm{a} \cos \phi-\mathrm{s})^{2}+(\mathrm{a} \sin \phi-\mathrm{c})^{2} \Rightarrow-\mathrm{a}^{2}+\mathrm{b}^{2}-\mathrm{c}^{2}+2 \mathrm{as} \cos \phi+2 \mathrm{ac} \sin \phi=\mathrm{s}^{2}
$$

This I/O relationship contains three construction parameters, namely a, b, c. Together with the Chebychev error L, there are four parameters to be determined. Therefore the function synthesis may be performed for four design points. Rewriting Eq. (7) in the polynomial form

$$
\delta_{i}\left(\mathbf{x}_{\mathbf{i}}\right)=\mathrm{F}\left(\mathbf{x}_{\mathbf{i}}\right)-\sum_{\mathrm{j}=1}^{3} \mathrm{P}_{\mathrm{j}} \mathrm{f}_{\mathrm{j}}\left(\mathbf{x}_{\mathbf{i}}\right)=(-1)^{\mathrm{i}+1} \mathrm{~L} \text { for } \mathrm{i}=1, \ldots, 4
$$

where

$$
P_{1}=-a^{2}+b^{2}-c^{2}, f_{1}\left(\mathbf{x}_{i}\right)=1, P_{2}=a, f_{2}\left(\mathbf{x}_{i}\right)=2 s_{i} \cos \phi_{i}, P_{3}=a c, f_{3}\left(\mathbf{x}_{i}\right)=2 \sin \phi_{i}, F\left(\mathbf{x}_{i}\right)=s_{i}^{2}
$$

$\mathbf{x}_{\mathbf{i}}=\left(\phi_{\mathrm{i}}, \mathrm{s}_{\mathrm{i}}\right)$ represents the $\mathrm{i}^{\text {th }}$ design point and $\delta_{\mathrm{i}}\left(\mathbf{x}_{\mathrm{i}}\right)= \pm \mathrm{L}$ is the error. The reason for selecting the objective function as $F\left(\mathbf{x}_{\mathbf{i}}\right)=\mathrm{s}^{2}$ is that this function solely comprises the output $\mathrm{s}$ and the error $\delta_{\mathrm{i}}\left(\mathbf{x}_{\mathbf{i}}\right)$ better represents the error in the output. Given the design points $\mathbf{x}_{\mathbf{i}}=\left(\phi_{\mathrm{i}}, \mathrm{s}_{\mathrm{i}}\right)$ for $\mathrm{i}=1, \ldots, 4, \mathrm{P}_{1}, \mathrm{P}_{2}, \mathrm{P}_{3}$ and $\mathrm{L}$ are determined via the Remez algorithm as explained in Section 2. Once $\mathrm{P}_{1}, \mathrm{P}_{2}, \mathrm{P}_{3}$ are determined, the construction parameters a, b and c are found from Eq. (9) as follows:

$$
\mathrm{a}=\mathrm{P}_{2}, \mathrm{c}=\frac{\mathrm{P}_{3}}{\mathrm{a}}, \mathrm{b}=\sqrt{\mathrm{P}_{1}+\mathrm{a}^{2}+\mathrm{c}^{2}}
$$

If any of a or c turns out to be negative, or if $\mathrm{b}$ is not real, the limits for $\phi_{\mathrm{i}}$ and/or $\mathrm{s}_{\mathrm{i}}$ shall be altered.

For the imaginary loop DEF (Alizade et al., 2013)

$$
\mathrm{e}^{2}=(1-\mathrm{s}+\mathrm{d} \cos \theta)^{2}+(-\mathrm{f}+\mathrm{d} \sin \theta)^{2} \Rightarrow \mathrm{d}^{2}-\mathrm{e}^{2}+\mathrm{f}^{2}+(1-\mathrm{s})^{2}+2 \mathrm{~d}(1-\mathrm{s}) \cos \theta-2 \mathrm{df} \sin \theta=0
$$

Eq. (11), once again, contains three construction parameters: d, e, f. Note that Eq. (7) and Eq. (11) have similar form. Again, there are four parameters to be determined and hence four design points are required. The polynomial form in Eq. (8) can be used, but this time 


$$
\mathrm{P}_{1}=\frac{\mathrm{d}^{2}-\mathrm{e}^{2}+\mathrm{f}^{2}}{2 \mathrm{df}}, \mathrm{f}_{1}\left(\mathbf{x}_{\mathrm{i}}\right)=1, \mathrm{P}_{2}=\frac{1}{\mathrm{f}}, \mathrm{f}_{2}\left(\mathbf{x}_{\mathrm{i}}\right)=\left(1-\mathrm{s}_{\mathrm{i}}\right) \cos \theta_{\mathrm{i}}, \mathrm{P}_{3}=\frac{1}{2 \mathrm{df}}, \mathrm{f}_{3}\left(\mathbf{x}_{\mathbf{i}}\right)=\left(1-\mathrm{s}_{\mathrm{i}}\right)^{2}, \mathrm{~F}\left(\mathbf{x}_{\mathbf{i}}\right)=\sin \theta_{\mathrm{i}} ; \mathbf{x}_{\mathrm{i}}=\left(\mathrm{s}_{\mathrm{i}}, \theta_{\mathrm{i}}\right)
$$

Given the design points $\mathbf{x}_{\mathrm{i}}=\left(\mathrm{s}_{\mathrm{i}}, \theta_{\mathrm{i}}\right)$ for $\mathrm{i}=1, \ldots, 4, \mathrm{P}_{1}, \mathrm{P}_{2}, \mathrm{P}_{3}$ and $\mathrm{L}$ are solved via Remez algorithm. The construction parameters $\mathrm{d}$, e and $\mathrm{f}$ are determined from Eq. (12) as follows:

$$
\mathrm{f}=\frac{1}{\mathrm{P}_{2}}, \mathrm{~d}=\frac{1}{2 \mathrm{P}_{3} \mathrm{f}}, \mathrm{e}=\sqrt{\mathrm{d}^{2}+\mathrm{f}^{2}-2 \mathrm{P}_{1} \mathrm{df}}
$$

\subsection{The Double-Planar 6R Mechanism with 7, 8 and 9 Parameters}

When the input and output angles are not measured from the same reference (x-axis in Fig. 2), we can define extra construction parameters as the location of the reference geometry with respect to the fixed frame. In this sense the input angle $\phi$ may be measured from an initial angle $\phi_{0}$. In this case, Eq. (7) can be modified as

$$
-\mathrm{a}^{2}+\mathrm{b}^{2}-\mathrm{c}^{2}+2 \mathrm{a} \operatorname{scos} \phi_{0} \cos \phi-2 \mathrm{as} \sin \phi_{0} \sin \phi+2 \mathrm{accos} \phi_{0} \sin \phi+2 \mathrm{ac} \sin \phi_{0} \cos \phi=\mathrm{s}^{2}
$$

Rewriting Eq. (14) in polynomial form

$$
\delta_{i}\left(\mathbf{x}_{i}\right)=F\left(\mathbf{x}_{i}\right)-\sum_{j=1}^{5} P_{j} f_{j}\left(\mathbf{x}_{i}\right)=(-1)^{i+1} L \text { for } \mathrm{i}=1, \ldots, 5
$$

where

$$
\begin{gathered}
\mathrm{P}_{1}=-\mathrm{a}^{2}+\mathrm{b}^{2}-\mathrm{c}^{2}, \mathrm{f}_{1}\left(\mathbf{x}_{\mathrm{i}}\right)=1, \mathrm{P}_{2}=\mathrm{a} \cos \phi_{0}, \mathrm{f}_{2}\left(\mathbf{x}_{\mathrm{i}}\right)=2 \mathrm{~s}_{\mathrm{i}} \cos \phi, \mathrm{P}_{3}=\mathrm{a} \sin \phi_{0}, \mathrm{f}_{3}\left(\mathbf{x}_{\mathrm{i}}\right)=-2 \mathrm{~s}_{\mathrm{i}} \sin \phi_{\mathrm{i}}, \mathrm{P}_{4}=\operatorname{accos} \phi_{0}, \\
\mathrm{f}_{4}\left(\mathbf{x}_{\mathrm{i}}\right)=2 \sin \phi_{\mathrm{i}}, \mathrm{P}_{5}=\mathrm{ac} \sin \phi_{0}, \mathrm{f}_{5}\left(\mathbf{x}_{\mathrm{i}}\right)=2 \cos \phi_{\mathrm{i}}, \mathrm{F}\left(\mathbf{x}_{\mathbf{i}}\right)=\mathrm{s}_{\mathrm{i}}{ }^{2} \text { and } \mathbf{x}_{\mathrm{i}}=\left(\phi_{\mathrm{i}}, \mathrm{s}_{\mathrm{i}}\right)
\end{gathered}
$$

$\mathrm{P}_{2}, \mathrm{P}_{3}, \mathrm{P}_{4}$ and $\mathrm{P}_{5}$ are dependent such that

$$
\mathrm{P}_{3} \mathrm{P}_{4}=\mathrm{P}_{2} \mathrm{P}_{5}
$$

Let $P_{5}=\lambda, P_{j}=\ell_{j} \lambda+m_{j}$ for $j=1, \ldots, 4$ and $L=\ell \lambda+m$. After finding $\ell_{j}$ and $m_{j}$ as explained in Section $2, \lambda$ is determined as follows:

$$
\begin{aligned}
\mathrm{P}_{3} \mathrm{P}_{4}-\mathrm{P}_{2} \mathrm{P}_{5}= & \left(\ell_{3} \lambda+\mathrm{m}_{3}\right)\left(\ell_{4} \lambda+\mathrm{m}_{4}\right)-\lambda\left(\ell_{2} \lambda+\mathrm{m}_{2}\right)=\left(\ell_{3} \ell_{4}-\ell_{2}\right) \lambda^{2}+\left(\ell_{3} \mathrm{~m}_{4}+\mathrm{m}_{3} \ell_{4}-\mathrm{m}_{2}\right) \lambda+\mathrm{m}_{3} \mathrm{~m}_{4}=0 \\
& \Rightarrow \lambda=\frac{-\left(\ell_{3} \mathrm{~m}_{4}+\mathrm{m}_{3} \ell_{4}-\mathrm{m}_{2}\right) \mp \sqrt{\left(\ell_{3} \mathrm{~m}_{4}+\mathrm{m}_{3} \ell_{4}-\mathrm{m}_{2}\right)^{2}-4 \mathrm{~m}_{3} \mathrm{~m}_{4}\left(\ell_{3} \ell_{4}-\ell_{2}\right)}}{2\left(\ell_{3} \ell_{4}-\ell_{2}\right)}
\end{aligned}
$$

Note that $\lambda$ has two solutions. The designer can choose the solution which yields the less error in the end. After determining $\lambda, P_{j}=\ell_{j} \lambda+m_{j}$ for $j=1, \ldots, 4$ and $L=\ell \lambda+m$ are determined. Using Eq. (16) the construction parameters $\mathrm{a}, \mathrm{b}, \mathrm{c}$ and $\phi_{0}$ in terms of $\mathrm{P}_{\mathrm{j}}$ are found as follows:

$$
\phi_{0}=\operatorname{atan} 2\left(\mathrm{P}_{2}, \mathrm{P}_{3}\right), \mathrm{a}=\sqrt{\mathrm{P}_{2}^{2}+\mathrm{P}_{3}^{2}}, \mathrm{c}=\frac{\sqrt{\mathrm{P}_{4}^{2}+\mathrm{P}_{5}^{2}}}{\mathrm{a}}, \mathrm{b}=\sqrt{\mathrm{P}_{1}+\mathrm{a}^{2}+\mathrm{c}^{2}}
$$

Note that all the construction parameters are determined uniquely and the solution is guaranteed provided that $\mathrm{P}_{1}+\mathrm{a}^{2}+\mathrm{c}^{2} \geq 0$. 
Similarly, one can introduce $\mathrm{s}_{0}$ into Eq. (7):

$$
\mathrm{b}^{2}=\left(\mathrm{a} \cos \phi-\mathrm{s}-\mathrm{s}_{0}\right)^{2}+(\mathrm{a} \sin \phi-\mathrm{c})^{2} \Rightarrow-\mathrm{a}^{2}+\mathrm{b}^{2}-\mathrm{c}^{2}-\mathrm{s}_{0}{ }^{2}+2 \mathrm{ac} \sin \phi+2 \mathrm{as} \cos \phi-2 \mathrm{~s}_{0} \mathrm{~s}+2 \mathrm{as}_{0} \cos \phi=\mathrm{s}^{2}
$$

Eq. (20) can be written in the polynomial form given in Eq. (15) where

$$
\begin{gathered}
\mathrm{P}_{1}=-\mathrm{a}^{2}+\mathrm{b}^{2}-\mathrm{c}^{2}-\mathrm{s}_{0}{ }^{2}, \mathrm{f}_{1}\left(\mathbf{x}_{\mathbf{i}}\right)=1, \mathrm{P}_{2}=\mathrm{ac}, \mathrm{f}_{2}\left(\mathbf{x}_{\mathbf{i}}\right)=2 \sin \phi_{\mathrm{i}}, \mathrm{P}_{3}=\mathrm{a}, \mathrm{f}_{3}\left(\mathbf{x}_{\mathbf{i}}\right)=2 \mathrm{~s}_{\mathrm{i}} \cos \phi_{\mathrm{i}}, \mathrm{P}_{4}=\mathrm{s}_{0}, \mathrm{f}_{4}\left(\mathbf{x}_{\mathbf{i}}\right)=-2 \mathrm{~s}_{\mathrm{i}}, \\
\mathrm{P}_{5}=\mathrm{as}_{0}, \mathrm{f}_{5}\left(\mathbf{x}_{\mathbf{i}}\right)=2 \cos \phi_{\mathrm{i}}, \mathrm{F}\left(\mathbf{x}_{\mathbf{i}}\right)=\mathrm{s}_{\mathrm{i}}{ }^{2}
\end{gathered}
$$

Note that

$$
\mathrm{P}_{5}=\mathrm{P}_{3} \mathrm{P}_{4}
$$

Once again, let $P_{5}=\lambda, P_{j}=\ell_{j} \lambda+m_{j}$ for $j=1, \ldots, 4$ and $L=\ell \lambda+m$. After finding $\ell_{j}$ and $m_{j}$ as explained in Section $2, \lambda$ is determined as follows:

$$
\begin{gathered}
\mathrm{P}_{3} \mathrm{P}_{4}-\mathrm{P}_{5}=\left(\ell_{3} \lambda+\mathrm{m}_{3}\right)\left(\ell_{4} \lambda+\mathrm{m}_{4}\right)-\lambda=\ell_{3} \ell_{4} \lambda^{2}+\left(\ell_{3} \mathrm{~m}_{4}+\mathrm{m}_{3} \ell_{4}-1\right) \lambda+\mathrm{m}_{3} \mathrm{~m}_{4}=0 \\
\Rightarrow \lambda=\frac{-\left(\ell_{3} \mathrm{~m}_{4}+\mathrm{m}_{3} \ell_{4}-1\right) \mp \sqrt{\left(\ell_{3} \mathrm{~m}_{4}+\mathrm{m}_{3} \ell_{4}-1\right)^{2}-4 \ell_{3} \ell_{4} \mathrm{~m}_{3} \mathrm{~m}_{4}}}{2 \ell_{3} \ell_{4}}
\end{gathered}
$$

$\lambda$ has two solutions. Having found $\lambda, P_{j}=\ell_{j} \lambda+m_{j}$ for $j=1, \ldots, 4$ and $L=\ell \lambda+m$. The construction parameters are solved uniquely from Eq. (21) as:

$$
\mathrm{a}=\mathrm{P}_{3}, \mathrm{~s}_{0}=\mathrm{P}_{4}, \mathrm{c}=\mathrm{P}_{2} / \mathrm{a}, \mathrm{b}=\sqrt{\mathrm{P}_{1}+\mathrm{a}^{2}+\mathrm{c}^{2}+\mathrm{s}_{0}^{2}}
$$

The solution is feasible if $\mathrm{P}_{2}, \mathrm{P}_{3}, \mathrm{P}_{4} \geq 0$ and $\mathrm{P}_{1}+\mathrm{a}^{2}+\mathrm{c}^{2}+\mathrm{s}_{0}^{2} \geq 0$.

Similar to introducing $\phi_{0}$, we can measure the output $\theta$ from a different reference with an initial angle of $\theta_{0}$ as shown in Fig. 2. Then Eq. (11) yields

$$
\mathrm{d}^{2}-\mathrm{e}^{2}+\mathrm{f}^{2}+(1-\mathrm{s})^{2}+2 \mathrm{~d}(1-\mathrm{s}) \cos \theta_{0} \cos \theta-2 \mathrm{~d}(1-\mathrm{s}) \sin \theta_{0} \sin \theta-2 \mathrm{df} \sin \theta_{0} \cos \theta-2 \mathrm{df} \cos \theta_{0} \sin \theta=0
$$

Eq. (25) can be written in the polynomial form given in Eq. (15) where

$$
\begin{gathered}
P_{1}=\frac{d^{2}-e^{2}+f^{2}}{2 d f \cos \theta_{0}}, f_{1}\left(\mathbf{x}_{\mathbf{i}}\right)=1, P_{2}=\frac{1}{2 d f \cos \theta_{0}}, f_{2}\left(\mathbf{x}_{i}\right)=\left(1-s_{i}\right)^{2}, P_{3}=\frac{1}{f}, f_{3}\left(\mathbf{x}_{i}\right)=\left(1-s_{i}\right) \cos \theta_{i}, \\
P_{4}=\tan \theta_{0}, f_{4}\left(\mathbf{x}_{i}\right)=-\cos \theta_{i}, P_{5}=\frac{\tan \theta_{0}}{f}, f_{5}\left(\mathbf{x}_{i}\right)=-\left(1-s_{i}\right) \sin \theta_{i}, F\left(\mathbf{x}_{i}\right)=\sin \theta_{i}
\end{gathered}
$$

Again $\mathrm{P}_{5}=\mathrm{P}_{3} \mathrm{P}_{4}$ and $\mathrm{P}_{5}=\lambda$ can be solved using Eq. (23). $\mathrm{P}_{\mathrm{j}}=\ell_{\mathrm{j}} \lambda+\mathrm{m}_{\mathrm{j}}$ for $\mathrm{j}=1, \ldots, 4$ and $\mathrm{L}=\ell \lambda+\mathrm{m}$ are determined and the construction parameters are solved from Eq. (26) as:

$$
\theta_{0}=\tan ^{-1} P_{4}, f=\frac{1}{P_{3}}, d=\frac{1}{2 P_{2} f \cos \theta_{0}}, e=\sqrt{d^{2}+f^{2}-2 d f \cos \theta_{0} P_{1}}
$$

Also it is possible to consider inclusion of $\mathrm{s}_{0}$ to loop DEF. However, inclusion of $\mathrm{s}_{0}$ can be done to either of the loops, not both. The next step is to include of both $\phi_{0}$ and $s_{0}$ to loop ABC. In that case, Eq. (14) can be modified as 


$$
\begin{aligned}
-\mathrm{a}^{2}+\mathrm{b}^{2} & -\mathrm{c}^{2}-\mathrm{s}_{0}{ }^{2}-2 \mathrm{~s}_{0} \mathrm{~s}+2 \mathrm{as} \cos \phi_{0} \cos \phi-2 \mathrm{as} \sin \phi_{0} \sin \phi \\
& +2 \mathrm{a}\left(\mathrm{s}_{0} \cos \phi_{0}+\mathrm{c} \sin \phi_{0}\right) \cos \phi-2 \mathrm{a}\left(\mathrm{s}_{0} \sin \phi_{0}-\mathrm{c} \cos \phi_{0}\right) \sin \phi=\mathrm{s}^{2}
\end{aligned}
$$

Eq. (28) can be written in polynomial form as

$$
\delta_{i}\left(\mathbf{x}_{\mathbf{i}}\right)=\mathrm{F}\left(\mathbf{x}_{\mathbf{i}}\right)-\sum_{\mathrm{j}=1}^{6} \mathrm{P}_{\mathrm{j}} \mathrm{f}_{\mathrm{j}}\left(\mathbf{x}_{\mathbf{i}}\right)=(-1)^{\mathrm{i}+1} \mathrm{~L} \text { for } \mathrm{i}=1, \ldots, 6
$$

where

$$
\begin{gathered}
\mathrm{P}_{1}=-\mathrm{a}^{2}+\mathrm{b}^{2}-\mathrm{c}^{2}-\mathrm{s}_{0}{ }^{2}, \mathrm{f}_{1}\left(\mathbf{x}_{\mathrm{i}}\right)=1, \mathrm{P}_{2}=\mathrm{s}_{0}, \mathrm{f}_{2}\left(\mathbf{x}_{\mathrm{i}}\right)=-2 \mathrm{~s}_{\mathrm{i}}, \mathrm{P}_{3}=\mathrm{a} \cos \phi_{0}, \mathrm{f}_{3}\left(\mathbf{x}_{\mathrm{i}}\right)=2 \mathrm{~s}_{\mathrm{i}} \cos \phi_{\mathrm{i}}, \\
\mathrm{P}_{4}=\mathrm{a} \sin \phi_{0}, \mathrm{f}_{4}\left(\mathbf{x}_{\mathbf{i}}\right)=-2 \mathrm{~s}_{\mathrm{i}} \sin \phi_{\mathrm{i}}, \mathrm{P}_{5}=\mathrm{a}\left(\mathrm{s}_{0} \cos \phi_{0}+\mathrm{c} \sin \phi_{0}\right), \mathrm{f}_{5}\left(\mathbf{x}_{\mathbf{i}}\right)=2 \cos \phi_{\mathrm{i}}, \\
\mathrm{P}_{6}=\mathrm{a}\left(\mathrm{s}_{0} \sin \phi_{0}-\mathrm{c} \cos \phi_{0}\right), \mathrm{f}_{6}\left(\mathbf{x}_{\mathbf{i}}\right)=-2 \sin \phi_{\mathrm{i}}, \mathrm{F}\left(\mathbf{x}_{\mathrm{i}}\right)=\mathrm{s}_{\mathrm{i}}{ }^{2}
\end{gathered}
$$

There are 5 construction parameters, but 6 polynomial coefficients. The dependency in between $\mathrm{P}_{\mathrm{j}}$ is obtained by eliminating $\mathrm{c}$ from $\mathrm{P}_{5}=\mathrm{P}_{2} \mathrm{P}_{3}+c \mathrm{P}_{4}$ and $\mathrm{P}_{6}=\mathrm{P}_{2} \mathrm{P}_{4}-c \mathrm{P}_{3}$ :

$$
\mathrm{P}_{3} \mathrm{P}_{5}+\mathrm{P}_{4} \mathrm{P}_{6}=\mathrm{P}_{2}\left(\mathrm{P}_{3}^{2}+\mathrm{P}_{4}^{2}\right)
$$

Let $P_{2}=\lambda$ (any of $P_{3}, \ldots, P_{6}$ may also be selected as $\lambda$ ), $P_{j}=\ell_{j} \lambda+m_{j}$ for $j=1,3, \ldots, 6$ and $\mathrm{L}=\ell \lambda+\mathrm{mL}=\ell \lambda+\mathrm{m} \cdot \ell_{\mathrm{j}}$ and $\mathrm{m}_{\mathrm{j}}$ can be solved linearly as explained in Section 2. Then, Eq. (31) is a cubic equation in terms of $\lambda$ and the three solutions for $\lambda$ can be found analytically. It is guaranteed that at least one of the solutions is real. In case of three real solutions, the designer can pick the solution which yields lesser error.

As an alternative, it is possible to introduce $s_{0}$ and $\theta_{0}$ simultaneously to loop DEF. This case is similar to loop $\mathrm{ABC}$ and again it is necessary to solve a cubic equation.

\subsection{The Double-Spherical 6R Mechanism with 8 Parameters}

A double-spherical 6R mechanism is shown in Fig. 3. The imaginary spherical 4-bar loops ABCD and AEFG share the common passive joint axis $\mathrm{A}$, which is along the line connecting the spherical loop centers $\mathrm{O}_{1}$ and $\mathrm{O}_{2}$. The $\mathrm{x}$-axis of the fixed coordinate system is chosen along $\mathrm{O}_{1} \mathrm{O}_{2}$ and the $\mathrm{y}$ axis is selected such that the $\mathrm{O}_{1} \mathrm{~B}$ revolute joint axis remains on the xy-plane. $\phi, \psi$ and $\theta$ are the respective input, passive joint and output angle. $\mathrm{O}_{1} \mathrm{D}$ and $\mathrm{O}_{2} \mathrm{E}$ axes are in general skew with a twist angle of $\gamma$. The radii of the spheres do not affect the I/O relationship, so without loss of generality, assume both radii as 1. Also, notice that the distance $\left|\mathrm{O}_{1} \mathrm{O}_{2}\right|$ has no effect on the I/O relationship. For the time being assume $\phi_{0}=\gamma=\theta_{0}=0$. 


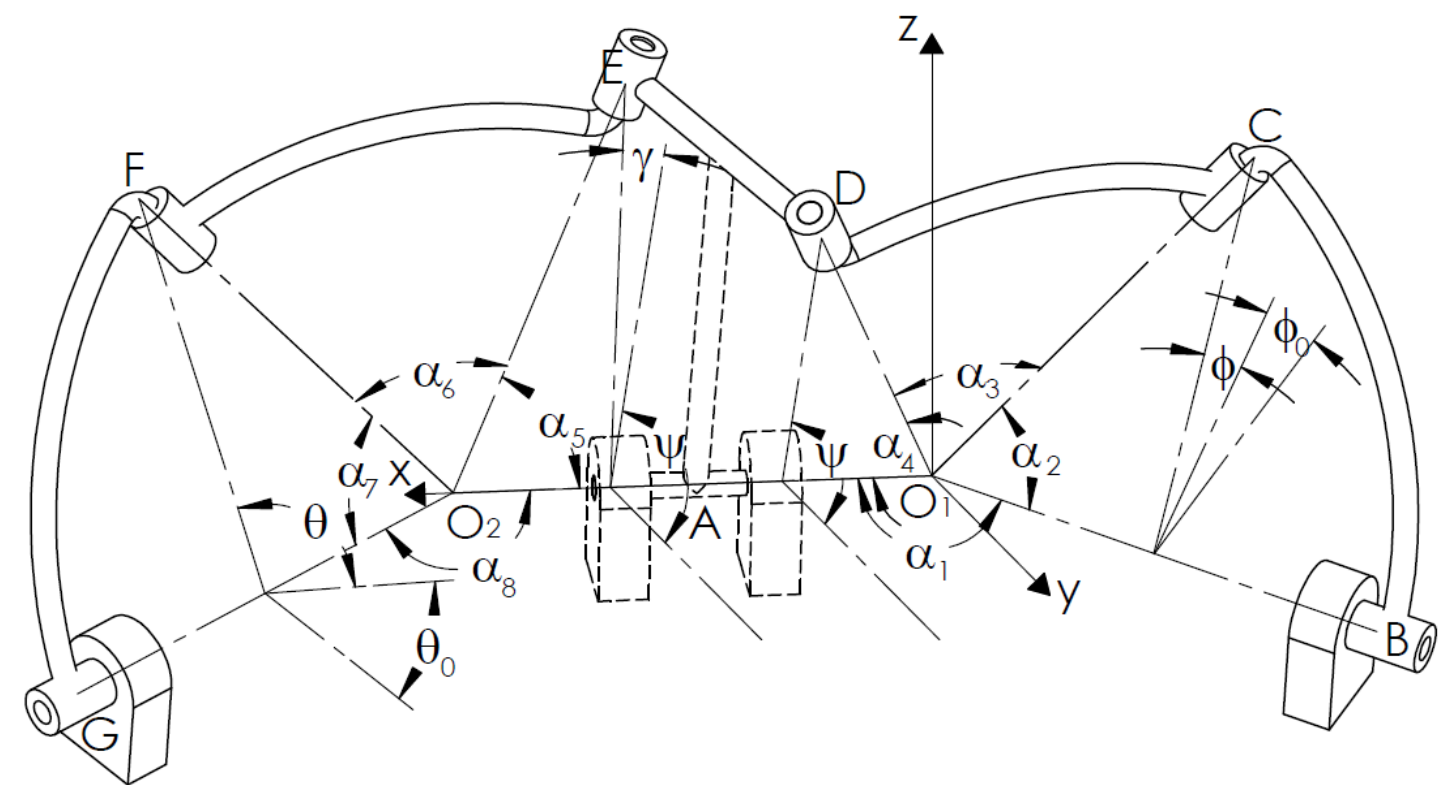

Fig. 3 Kinematic representation of the double-spherical 6R linkage

For the imaginary loop ABCD the I/O equation reads (Alizade et al., 2013)

$$
\begin{gathered}
\cos \alpha_{1} \cos \alpha_{2} \cos \alpha_{4}-\cos \alpha_{3}-\sin \alpha_{1} \sin \alpha_{2} \cos \alpha_{4} \cos \phi+\sin \alpha_{1} \cos \alpha_{2} \sin \alpha_{4} \cos \psi \\
+\cos \alpha_{1} \sin \alpha_{2} \sin \alpha_{4} \cos \phi \cos \psi+\sin \alpha_{2} \sin \alpha_{4} \sin \phi \sin \psi=0
\end{gathered}
$$

Eq. (32) contains four construction parameters: $\alpha_{1}, \alpha_{2}, \alpha_{3}, \alpha_{4}$. Together with the Chebychev error L, there are five parameters to be determined. The function synthesis may be performed for five design points. Writing Eq. (32) in polynomial form:

$$
\delta_{i}\left(\mathbf{x}_{\mathbf{i}}\right)=F\left(\mathbf{x}_{\mathbf{i}}\right)-\sum_{j=1}^{4} \mathrm{P}_{\mathrm{j}}\left(\mathbf{x}_{\mathrm{i}}\right)=(-1)^{\mathrm{i}+1} \mathrm{~L} \text { for } \mathrm{i}=1, \ldots, 5
$$

where

$$
\begin{gathered}
\mathrm{P}_{1}=\frac{\cos \alpha_{3}-\cos \alpha_{1} \cos \alpha_{2} \cos \alpha_{4}}{\sin \alpha_{1} \cos \alpha_{2} \sin \alpha_{4}}, \mathrm{f}_{1}\left(\mathbf{x}_{\mathbf{i}}\right)=1, \mathrm{P}_{2}=\frac{\tan \alpha_{2}}{\tan \alpha_{4}}, \mathrm{f}_{2}\left(\mathbf{x}_{\mathrm{i}}\right)=\cos \phi_{\mathrm{i}}, \mathrm{P}_{3}=\frac{\tan \alpha_{2}}{\tan \alpha_{1}}, \\
\mathrm{f}_{3}\left(\mathbf{x}_{\mathrm{i}}\right)=-\cos \phi_{\mathrm{i}} \cos \psi_{\mathrm{i}}, \mathrm{P}_{4}=\frac{\tan \alpha_{2}}{\sin \alpha_{1}}, \mathrm{f}_{4}\left(\mathbf{x}_{\mathbf{i}}\right)=-\sin \phi_{\mathrm{i}} \sin \psi_{\mathrm{i}}, \mathrm{F}\left(\mathbf{x}_{\mathbf{i}}\right)=\cos \psi_{\mathrm{i}}
\end{gathered}
$$

$\mathbf{x}_{\mathrm{i}}=\left(\phi_{\mathrm{i}}, \psi_{\mathrm{i}}\right)$ represents the $\mathrm{i}^{\text {th }}$ design point and $\delta_{\mathrm{i}}\left(\mathbf{x}_{\mathbf{i}}\right) . \mathrm{P}_{\mathrm{j}}$ are solved linearly from Eq. (33) using the Remez algorithm and then the construction parameters are solved from Eq. (34) as follows:

$$
\begin{aligned}
& \alpha_{1}=\cos ^{-1} \frac{\mathrm{P}_{3}}{\mathrm{P}_{4}}, \alpha_{2}=\tan ^{-1}\left(\mathrm{P}_{3} \tan \alpha_{1}\right), \alpha_{4}=\tan ^{-1} \frac{\tan \alpha_{2}}{\mathrm{P}_{2}}, \\
& \alpha_{3}=\cos ^{-1}\left(\cos \alpha_{1} \cos \alpha_{2} \cos \alpha_{4}+\mathrm{P}_{1} \sin \alpha_{1} \cos \alpha_{2} \sin \alpha_{4}\right)
\end{aligned}
$$

Notice that the solution for the construction parameters is not unique. For example there are two alternative solutions for $\alpha_{1}: \cos ^{-1}\left(\mathrm{P}_{3} / \mathrm{P}_{4}\right)$ and $-\cos ^{-1}\left(\mathrm{P}_{3} / \mathrm{P}_{4}\right)$. In Eq. (35) three are 16 possible solutions. The solution/solutions which yield the desired function generation should be determined by either constructing a virtual/actual model of the mechanism or checking the input/output values. 
For loop AEFG the I/O equation for $\gamma=0$ is given by (Alizade et al., 2013)

$$
\begin{gathered}
\cos \alpha_{5} \cos \alpha_{7} \cos \alpha_{8}-\cos \alpha_{6}+\sin \alpha_{5} \cos \alpha_{7} \sin \alpha_{8} \cos \psi-\sin \alpha_{5} \sin \alpha_{7} \cos \alpha_{8} \cos \theta \cos \psi \\
+\sin \alpha_{5} \sin \alpha_{7} \sin \theta \sin \psi+\cos \alpha_{5} \sin \alpha_{7} \sin \alpha_{8} \cos \theta=0
\end{gathered}
$$

Eq. (36) can be written in polynomial form given in Eq. (33) where

$$
\begin{gathered}
\mathrm{P}_{1}=\frac{\cos \alpha_{6}-\cos \alpha_{5} \cos \alpha_{7} \cos \alpha_{8}}{\cos \alpha_{5} \sin \alpha_{7} \sin \alpha_{8}}, \mathrm{f}_{1}\left(\mathbf{x}_{\mathbf{i}}\right)=1, \mathrm{P}_{2}=-\frac{\tan \alpha_{5}}{\tan \alpha_{7}}, \mathrm{f}_{2}\left(\mathbf{x}_{\mathbf{i}}\right)=\cos \psi_{\mathrm{i}}, \mathrm{P}_{3}=\frac{\tan \alpha_{5}}{\tan \alpha_{8}}, \mathrm{f}_{3}\left(\mathbf{x}_{\mathbf{i}}\right)=\cos \theta_{\mathrm{i}} \cos \psi_{\mathrm{i}}, \\
\mathrm{P}_{4}=-\frac{\tan \alpha_{5}}{\sin \alpha_{8}}, \mathrm{f}_{4}\left(\mathbf{x}_{\mathrm{i}}\right)=\sin \theta_{\mathrm{i}} \sin \psi_{\mathrm{i}}, \mathrm{F}\left(\mathbf{x}_{\mathbf{i}}\right)=\cos \theta_{\mathrm{i}} \text { and } \mathbf{x}_{\mathrm{i}}=\left(\psi_{\mathrm{i}}, \theta_{\mathrm{i}}\right)
\end{gathered}
$$

For given 5 design points, $\mathbf{x}_{\mathrm{i}}=\left(\phi_{\mathrm{i}}, \psi_{\mathrm{i}}\right), \mathrm{P}_{\mathrm{j}}$ are solved linearly from Eq. (33) using the Remez algorithm and then, the construction parameters are solved from Eq. (37) as follows:

$$
\begin{gathered}
\alpha_{8}=\cos ^{-1}\left(-\frac{\mathrm{P}_{3}}{\mathrm{P}_{4}}\right), \alpha_{5}=\tan ^{-1}\left(\mathrm{P}_{3} \tan \alpha_{8}\right), \alpha_{7}=\tan ^{-1}-\frac{\tan \alpha_{5}}{\mathrm{P}_{2}}, \\
\alpha_{6}=\cos ^{-1}\left(\cos \alpha_{5} \cos \alpha_{7} \cos \alpha_{8}+\mathrm{P}_{1} \cos \alpha_{5} \sin \alpha_{7} \sin \alpha_{8}\right)
\end{gathered}
$$

\subsection{The Double-Spherical 6R Mechanism with 9, 10 and 11 Parameters}

When extra construction parameter $\phi_{0}$ is added into Eq. (32):

$$
\begin{gathered}
\cos \alpha_{1} \cos \alpha_{2} \cos \alpha_{4}-\cos \alpha_{3}-\sin \alpha_{1} \sin \alpha_{2} \cos \alpha_{4} \cos \phi_{0} \cos \phi+\sin \alpha_{1} \sin \alpha_{2} \cos \alpha_{4} \sin \phi_{0} \sin \phi \\
+\sin \alpha_{1} \cos \alpha_{2} \sin \alpha_{4} \cos \psi+\cos \alpha_{1} \sin \alpha_{2} \sin \alpha_{4} \cos \phi_{0} \cos \phi \cos \psi \\
-\cos \alpha_{1} \sin \alpha_{2} \sin \alpha_{4} \sin \phi_{0} \sin \phi \cos \psi+\sin \alpha_{2} \sin \alpha_{4} \sin \phi_{0} \cos \phi \sin \psi+\sin \alpha_{2} \sin \alpha_{4} \cos \phi_{0} \sin \phi \sin \psi=0
\end{gathered}
$$

Eq. (39) can be written in polynomial form as

$$
\delta_{i}\left(\mathbf{x}_{i}\right)=F\left(\mathbf{x}_{i}\right)-\sum_{j=1}^{7} P_{j} f_{j}\left(\mathbf{x}_{i}\right)=(-1)^{i+1} L \text { for } i=1, \ldots, 6
$$

where

$$
\begin{gathered}
\mathrm{P}_{1}=\frac{\cos \alpha_{1} \cos \alpha_{2} \cos \alpha_{4}-\cos \alpha_{3}}{\cos \alpha_{1} \sin \alpha_{2} \sin \alpha_{4} \sin \phi_{0}}, \mathrm{f}_{1}\left(\mathbf{x}_{\mathrm{i}}\right)=1, \mathrm{P}_{2}=\frac{\tan \alpha_{1}}{\tan \alpha_{4}}, \mathrm{f}_{2}\left(\mathbf{x}_{\mathrm{i}}\right)=\sin \phi_{\mathrm{i}}, \mathrm{P}_{3}=\frac{\tan \alpha_{1}}{\tan \alpha_{2} \sin \phi_{0}}, \\
\mathrm{f}_{3}\left(\mathbf{x}_{\mathrm{i}}\right)=\cos \psi_{\mathrm{i}}, \mathrm{P}_{4}=\frac{1}{\tan \phi_{0}}, \mathrm{f}_{4}\left(\mathbf{x}_{\mathrm{i}}\right)=\cos \phi_{\mathrm{i}} \cos \psi_{\mathrm{i}}, \mathrm{P}_{5}=\frac{1}{\cos \alpha_{1}}, \mathrm{f}_{5}\left(\mathbf{x}_{\mathrm{i}}\right)=\cos \phi_{\mathrm{i}} \sin \psi_{\mathrm{i}}, \\
\mathrm{P}_{6}=-\frac{\tan \alpha_{1}}{\tan \alpha_{4} \tan \phi_{0}}, \mathrm{f}_{6}\left(\mathbf{x}_{\mathrm{i}}\right)=\cos \phi_{\mathrm{i}}, \mathrm{P}_{7}=\frac{1}{\cos \alpha_{1} \tan \phi_{0}}, \mathrm{f}_{7}\left(\mathbf{x}_{\mathrm{i}}\right)=\sin \phi_{\mathrm{i}} \sin \psi_{\mathrm{i}}, \mathrm{F}\left(\mathbf{x}_{\mathrm{i}}\right)=\sin \phi_{\mathrm{i}} \cos \psi_{\mathrm{i}}
\end{gathered}
$$

There are five construction parameters, i.e. $\alpha_{1}, \alpha_{2}, \alpha_{3}, \alpha_{4}$ and $\phi_{0}$, however there are seven $\mathrm{P}_{\mathrm{j}}$. Indeed, two of the $\mathrm{P}_{\mathrm{j}}$ can be represented in terms of other as

$$
\mathrm{P}_{6}=-\mathrm{P}_{2} \mathrm{P}_{4} \text { and } \mathrm{P}_{7}=\mathrm{P}_{4} \mathrm{P}_{5}
$$

Let $\mathrm{P}_{6}=\lambda_{1}, \mathrm{P}_{7}=\lambda_{2}, \mathrm{P}_{\mathrm{j}}=\ell_{\mathrm{j}}+\mathrm{m}_{\mathrm{j}} \lambda_{1}+\mathrm{n}_{\mathrm{j}} \lambda_{2}$ for $\mathrm{j}=1, \ldots, 5$ and $\mathrm{L}=\ell+\mathrm{m} \lambda_{1}+\mathrm{n} \lambda_{2} \cdot \ell_{\mathrm{j}}, \mathrm{m}_{\mathrm{j}}$ and $\mathrm{n}_{\mathrm{j}}$ are found as 
explained in Section 2. Writing Eq. (42) in terms of $\lambda_{1}$ and $\lambda_{2}$ :

$$
\begin{aligned}
& \mathrm{P}_{2} \mathrm{P}_{4}+\mathrm{P}_{6}=\mathrm{m}_{2} \mathrm{~m}_{4} \lambda_{1}^{2}+\mathrm{n}_{2} \mathrm{n}_{4} \lambda_{2}^{2}+\left(\mathrm{m}_{2} \mathrm{n}_{4}+\mathrm{n}_{2} \mathrm{~m}_{4}\right) \lambda_{1} \lambda_{2}+\left(\ell_{2} \mathrm{~m}_{4}+\mathrm{m}_{2} \ell_{4}+1\right) \lambda_{1}+\left(\ell_{2} \mathrm{n}_{4}+\mathrm{n}_{2} \ell_{4}\right) \lambda_{2}+\ell_{2} \ell_{4}=0 \\
& \mathrm{P}_{4} \mathrm{P}_{5}-\mathrm{P}_{7}=\mathrm{m}_{4} \mathrm{~m}_{5} \lambda_{1}^{2}+\mathrm{n}_{4} \mathrm{n}_{5} \lambda_{2}^{2}+\left(\mathrm{m}_{4} \mathrm{n}_{5}+\mathrm{n}_{4} \mathrm{~m}_{5}\right) \lambda_{1} \lambda_{2}+\left(\ell_{4} \mathrm{~m}_{5}+\mathrm{m}_{4} \ell_{5}-1\right) \lambda_{1}+\left(\ell_{4} \mathrm{n}_{5}+\mathrm{n}_{4} \ell_{5}\right) \lambda_{2}+\ell_{4} \ell_{5}=0
\end{aligned}
$$

As shown in (Alizade, Kilit, 2005), when $\lambda_{2}$ is eliminated from Eq. (43) to obtain a third order equation in terms of $\lambda_{1}$, which can be solved analytically. At this point, it should be emphasized that the $P_{j}$ in Eq. (41) are selected as such on purpose so that Eq. (42) is obtained and hence, there are three solutions.

For other cases, the fourth order term which appears after elimination in Eq. (43), does not vanish, thus analytical solution is not possible and it is possible that there are no real solutions.

After determining $\lambda_{1}$ and $\lambda_{2}, P_{j}=\ell_{j}+m_{j} \lambda_{1}+n_{j} \lambda_{2}$ for $j=1, \ldots, 5$ and $L=\ell+m \lambda_{1}+n \lambda_{2}$ are determined. From Eq. (41) the construction parameters $\alpha_{1}, \alpha_{2}, \alpha_{3}, \alpha_{4}$ and $\phi_{0}$ are found as follows:

$$
\begin{gathered}
\phi_{0}=\tan ^{-1} \frac{1}{\mathrm{P}_{4}}, \alpha_{1}=\cos ^{-1} \frac{1}{\mathrm{P}_{5}}, \alpha_{2}=\tan ^{-1} \frac{\tan \alpha_{1}}{\mathrm{P}_{3} \sin \phi_{0}}, \alpha_{4}=\tan ^{-1} \frac{\tan \alpha_{1}}{\mathrm{P}_{2}}, \\
\alpha_{3}=\cos ^{-1}\left(\cos \alpha_{1} \cos \alpha_{2} \cos \alpha_{4}-\mathrm{P}_{1} \cos \alpha_{1} \sin \alpha_{2} \sin \alpha_{4} \sin \phi_{0}\right)
\end{gathered}
$$

When the twist angle $\gamma$ in between $\mathrm{O}_{1} \mathrm{D}$ and $\mathrm{O}_{2} \mathrm{E}$ in Fig. 3 is taken into account Eq. (32) becomes

$$
\begin{gathered}
\cos \alpha_{1} \cos \alpha_{2} \cos \alpha_{4}-\cos \alpha_{3}-\sin \alpha_{1} \sin \alpha_{2} \cos \alpha_{4} \cos \phi+\sin \alpha_{1} \cos \alpha_{2} \sin \alpha_{4} \cos \gamma \cos \psi \\
-\sin \alpha_{1} \cos \alpha_{2} \sin \alpha_{4} \sin \gamma \sin \psi+\cos \alpha_{1} \sin \alpha_{2} \sin \alpha_{4} \cos \gamma \cos \phi \cos \psi \\
-\cos \alpha_{1} \sin \alpha_{2} \sin \alpha_{4} \sin \gamma \cos \phi \sin \psi+\sin \alpha_{2} \sin \alpha_{4} \sin \gamma \sin \phi \cos \psi+\sin \alpha_{2} \sin \alpha_{4} \cos \gamma \sin \phi \sin \psi=0
\end{gathered}
$$

Eq. (45) can be written in polynomial form in Eq. (40) where

$$
\begin{gathered}
\mathrm{P}_{1}=\frac{\cos \alpha_{1} \cos \alpha_{2} \cos \alpha_{4}-\cos \alpha_{3}}{\cos \alpha_{1} \sin \alpha_{2} \sin \alpha_{4} \sin \gamma}, \mathrm{f}_{1}\left(\mathbf{x}_{\mathrm{i}}\right)=1, \mathrm{P}_{2}=\frac{\tan \alpha_{1}}{\tan \alpha_{4} \sin \gamma}, \mathrm{f}_{2}\left(\mathbf{x}_{\mathrm{i}}\right)=-\cos \phi_{\mathrm{i}}, \mathrm{P}_{3}=\frac{\tan \alpha_{1}}{\tan \alpha_{2}}, \mathrm{f}_{3}\left(\mathbf{x}_{\mathrm{i}}\right)=-\sin \psi_{\mathrm{i}} \\
\mathrm{P}_{4}=\frac{1}{\tan \gamma}, \mathrm{f}_{4}\left(\mathbf{x}_{\mathrm{i}}\right)=\cos \phi_{\mathrm{i}} \cos \psi_{\mathrm{i}}, \mathrm{P}_{5}=\frac{1}{\cos \alpha_{1}}, \mathrm{f}_{5}\left(\mathbf{x}_{\mathbf{i}}\right)=\sin \phi_{\mathrm{i}} \cos \psi_{\mathrm{i}}, \mathrm{P}_{6}=-\frac{\tan \alpha_{1}}{\tan \alpha_{2} \tan \gamma}, \mathrm{f}_{6}\left(\mathbf{x}_{\mathrm{i}}\right)=-\cos \psi_{\mathrm{i}} \\
\mathrm{P}_{7}=\frac{1}{\cos \alpha_{1} \tan \gamma}, \mathrm{f}_{7}\left(\mathbf{x}_{\mathrm{i}}\right)=\sin \phi_{\mathrm{i}} \sin \psi_{\mathrm{i}}, \mathrm{F}\left(\mathbf{x}_{\mathrm{i}}\right)=\cos \phi_{\mathrm{i}} \sin \psi_{\mathrm{i}}
\end{gathered}
$$

$\mathrm{P}_{6}$ and $\mathrm{P}_{7}$ depend on other $\mathrm{P}_{\mathrm{j}}$ as

$$
\mathrm{P}_{6}=-\mathrm{P}_{3} \mathrm{P}_{4} \text { and } \mathrm{P}_{7}=\mathrm{P}_{4} \mathrm{P}_{5}
$$

which has the same form as in Eq. (42) and yield there solutions similar to the previous case. The construction parameters are obtained from Eq. (46) as follows:

$$
\begin{gathered}
\gamma=\tan ^{-1} \frac{1}{\mathrm{P}_{4}}, \alpha_{1}=\cos ^{-1} \frac{1}{\mathrm{P}_{5}}, \alpha_{2}=\tan ^{-1} \frac{\tan \alpha_{1}}{\mathrm{P}_{3}}, \alpha_{4}=\tan ^{-1} \frac{\tan \alpha_{1}}{\mathrm{P}_{2} \sin \gamma} \\
\alpha_{3}=\cos ^{-1}\left(\cos \alpha_{1} \cos \alpha_{2} \cos \alpha_{4}-\mathrm{P}_{1} \cos \alpha_{1} \sin \alpha_{2} \sin \alpha_{4} \sin \gamma\right)
\end{gathered}
$$

The twist angle $\gamma$ can also be included in Eq. (36) to replace $\psi$ by $\gamma+\psi$ :

$$
\begin{gathered}
\cos \alpha_{5} \cos \alpha_{7} \cos \alpha_{8}-\cos \alpha_{6}+\cos \alpha_{5} \sin \alpha_{7} \sin \alpha_{8} \cos \theta+\sin \alpha_{5} \cos \alpha_{7} \sin \alpha_{8} \cos \gamma \cos \psi \\
-\sin \alpha_{5} \cos \alpha_{7} \sin \alpha_{8} \sin \gamma \sin \psi-\sin \alpha_{5} \sin \alpha_{7} \cos \alpha_{8} \cos \gamma \cos \theta \cos \psi \\
+\sin \alpha_{5} \sin \alpha_{7} \cos \alpha_{8} \sin \gamma \cos \theta \sin \psi+\sin \alpha_{5} \sin \alpha_{7} \cos \gamma \sin \theta \sin \psi+\sin \alpha_{5} \sin \alpha_{7} \sin \gamma \sin \theta \cos \psi=0
\end{gathered}
$$


Writing Eq. (49) in polynomial form Eq. (40), the $\mathrm{P}_{\mathrm{j}}$ are selected as

$$
\begin{gathered}
\mathrm{P}_{1}=\frac{\cos \alpha_{5} \cos \alpha_{7} \cos \alpha_{8}-\cos \alpha_{6}}{\sin \alpha_{5} \sin \alpha_{7} \cos \alpha_{8} \cos \gamma}, \mathrm{f}_{1}\left(\mathbf{x}_{\mathrm{i}}\right)=1, \mathrm{P}_{2}=\frac{\tan \alpha_{8}}{\tan \alpha_{7}}, \mathrm{f}_{2}\left(\mathbf{x}_{\mathrm{i}}\right)=\cos \psi_{\mathrm{i}}, \mathrm{P}_{3}=\tan \gamma, \mathrm{f}_{3}\left(\mathbf{x}_{\mathrm{i}}\right)=\cos \theta_{\mathrm{i}} \sin \psi_{\mathrm{i}} \\
\mathrm{P}_{4}=\frac{\tan \alpha_{8}}{\tan \alpha_{5} \cos \gamma}, \mathrm{f}_{4}\left(\mathbf{x}_{\mathbf{i}}\right)=\cos \theta_{\mathrm{i}}, \mathrm{P}_{5}=\frac{1}{\cos \alpha_{8}}, \mathrm{f}_{5}\left(\mathbf{x}_{\mathrm{i}}\right)=\sin \theta_{\mathrm{i}} \sin \psi_{\mathrm{i}}, \mathrm{P}_{6}=-\frac{\tan \alpha_{8} \tan \gamma}{\tan \alpha_{7}}, \mathrm{f}_{6}\left(\mathbf{x}_{\mathrm{i}}\right)=\sin \psi_{\mathrm{i}} \\
\mathrm{P}_{7}=\frac{\tan \gamma}{\cos \alpha_{8}}, \mathrm{f}_{7}\left(\mathbf{x}_{\mathrm{i}}\right)=\sin \theta_{\mathrm{i}} \cos \psi_{\mathrm{i}}, \mathrm{F}\left(\mathbf{x}_{\mathrm{i}}\right)=\cos \theta_{\mathrm{i}} \cos \psi_{\mathrm{i}}
\end{gathered}
$$

$\mathrm{P}_{6}$ and $\mathrm{P}_{7}$ depend on other $\mathrm{P}_{\mathrm{j}}$ as

$$
\mathrm{P}_{6}=-\mathrm{P}_{2} \mathrm{P}_{3} \text { and } \mathrm{P}_{7}=\mathrm{P}_{3} \mathrm{P}_{5}
$$

which has the same form as in Eq. (42) and yield three solutions. The construction parameters are obtained from Eq. (50) as follows:

$$
\begin{gathered}
\gamma=\tan ^{-1} \mathrm{P}_{3}, \alpha_{8}=\cos ^{-1} \frac{1}{\mathrm{P}_{5}}, \alpha_{7}=\tan ^{-1}\left(-\frac{\tan \alpha_{8} \tan \gamma}{\mathrm{P}_{6}}\right), \alpha_{5}=\tan ^{-1} \frac{\tan \alpha_{8}}{\mathrm{P}_{4} \cos \gamma}, \\
\alpha_{6}=\cos ^{-1}\left(\cos \alpha_{5} \cos \alpha_{7} \cos \alpha_{8}-\mathrm{P}_{1} \sin \alpha_{5} \sin \alpha_{7} \cos \alpha_{8} \cos \gamma\right)
\end{gathered}
$$

Next, we can introduce the extra parameter $\theta_{0}$ in order to replace $\theta$ by $\theta_{0}+\theta$ in Eq. (36):

$$
\begin{gathered}
\cos \alpha_{5} \cos \alpha_{7} \cos \alpha_{8}-\cos \alpha_{6}+\sin \alpha_{5} \cos \alpha_{7} \sin \alpha_{8} \cos \psi-\sin \alpha_{5} \sin \alpha_{7} \cos \alpha_{8} \cos \theta_{0} \cos \theta \cos \psi \\
+\sin \alpha_{5} \sin \alpha_{7} \cos \alpha_{8} \sin \theta_{0} \sin \theta \cos \psi+\sin \alpha_{5} \sin \alpha_{7} \cos \theta_{0} \sin \theta \sin \psi+\sin \alpha_{5} \sin \alpha_{7} \sin \theta_{0} \cos \theta \sin \psi \\
+\cos \alpha_{5} \sin \alpha_{7} \sin \alpha_{8} \cos \theta_{0} \cos \theta-\cos \alpha_{5} \sin \alpha_{7} \sin \alpha_{8} \sin \theta_{0} \sin \theta=0
\end{gathered}
$$

Writing Eq. (53) in polynomial form Eq. (40), the $\mathrm{P}_{\mathrm{j}}$ are selected as

$$
\begin{gathered}
\mathrm{P}_{1}=\frac{\cos \alpha_{5} \cos \alpha_{7} \cos \alpha_{8}-\cos \alpha_{6}}{\sin \alpha_{5} \sin \alpha_{7} \cos \alpha_{8} \cos \theta_{0}}, \mathrm{f}_{1}\left(\mathbf{x}_{\mathbf{i}}\right)=1, \mathrm{P}_{2}=\frac{\tan \alpha_{8}}{\tan \alpha_{7} \cos \theta_{0}}, \mathrm{f}_{2}\left(\mathbf{x}_{\mathbf{i}}\right)=\cos \psi_{\mathrm{i}}, \mathrm{P}_{3}=\tan \theta_{0}, \\
\mathrm{f}_{3}\left(\mathbf{x}_{\mathbf{i}}\right)=\cos \psi_{\mathrm{i}} \sin \theta_{\mathrm{i}}, \mathrm{P}_{4}=\frac{1}{\cos \alpha_{8}}, \mathrm{f}_{4}\left(\mathbf{x}_{\mathbf{i}}\right)=\sin \psi_{\mathrm{i}} \sin \theta_{\mathrm{i}}, \mathrm{P}_{5}=\frac{\tan \alpha_{8}}{\tan \alpha_{5}}, \mathrm{f}_{5}\left(\mathbf{x}_{\mathbf{i}}\right)=\cos \theta_{\mathrm{i}}, \mathrm{P}_{6}=-\frac{\tan \alpha_{8} \tan \theta_{0}}{\tan \alpha_{5}} \\
\mathrm{f}_{6}\left(\mathbf{x}_{\mathbf{i}}\right)=\sin \theta_{\mathrm{i}}, \mathrm{P}_{7}=\frac{\tan \theta_{0}}{\cos \alpha_{8}}, \mathrm{f}_{7}\left(\mathbf{x}_{\mathbf{i}}\right)=\sin \psi_{\mathrm{i}} \cos \theta_{\mathrm{i}}, \mathrm{F}\left(\mathbf{x}_{\mathbf{i}}\right)=\cos \psi_{\mathrm{i}} \cos \theta_{\mathrm{i}}
\end{gathered}
$$

$\mathrm{P}_{6}$ and $\mathrm{P}_{7}$ depend on other $\mathrm{P}_{\mathrm{j}}$ as

$$
\mathrm{P}_{6}=-\mathrm{P}_{3} \mathrm{P}_{5} \text { and } \mathrm{P}_{7}=\mathrm{P}_{3} \mathrm{P}_{4}
$$

which has the same form as in Eq. (42) and yield three solutions. The construction parameters are obtained from Eq. (54) as follows:

$$
\begin{gathered}
\theta_{0}=\tan ^{-1} \mathrm{P}_{3}, \alpha_{8}=\cos ^{-1} \frac{1}{\mathrm{P}_{4}}, \alpha_{7}=\tan ^{-1} \frac{\tan \alpha_{8}}{\mathrm{P}_{2} \cos \theta_{0}}, \alpha_{5}=\tan ^{-1} \frac{\tan \alpha_{8}}{\mathrm{P}_{5}}, \\
\alpha_{6}=\cos ^{-1}\left(\cos \alpha_{5} \cos \alpha_{7} \cos \alpha_{8}-\mathrm{P}_{1} \sin \alpha_{5} \sin \alpha_{7} \cos \alpha_{8} \cos \theta_{0}\right)
\end{gathered}
$$

It is also possible to include both of $\phi_{0}$ and $\gamma$ in loop ABCD and both of $\gamma$ and $\theta_{0}$ in loop AEFG. This case is already studied in (Alizade, Gezgin, 2011), where it is necessary to define six nonlinear parameters $\lambda_{k}$ for $k=1, \ldots, 6$. The solution for $\lambda_{k}$ necessitates numerical solution. 


\subsection{Plano-Spherical 6R Mechanism with 7 Parameters}

A plano-spherical 6R linkage is depicted in Fig. 4, where $\phi$ is the input and $\theta$ is the output, or vice versa. The link length definitions for the spherical and planar parts are the same as for the corresponding imaginary loops of the double-planar and double-spherical linkages. In general, there is a twist angle $\gamma$ in between $\mathrm{O}_{1} \mathrm{D}^{\prime}$ and $\mathrm{AE}$ directions. The $\mathrm{x}$-axis direction of the fixed coordinate system is selected to be parallel to the joint axis directions of the planar loop. The y-axis is selected such that the xy-plane includes the $\mathrm{O}_{1} \mathrm{~B}$ axis of the spherical loop and the $\mathrm{z}$-axis is along the common normal of $\mathrm{O}_{1} \mathrm{~B}$ and $\mathrm{G}$ rotation axes. For the time being assume $\phi_{0}=\gamma=\theta_{0}=0$.

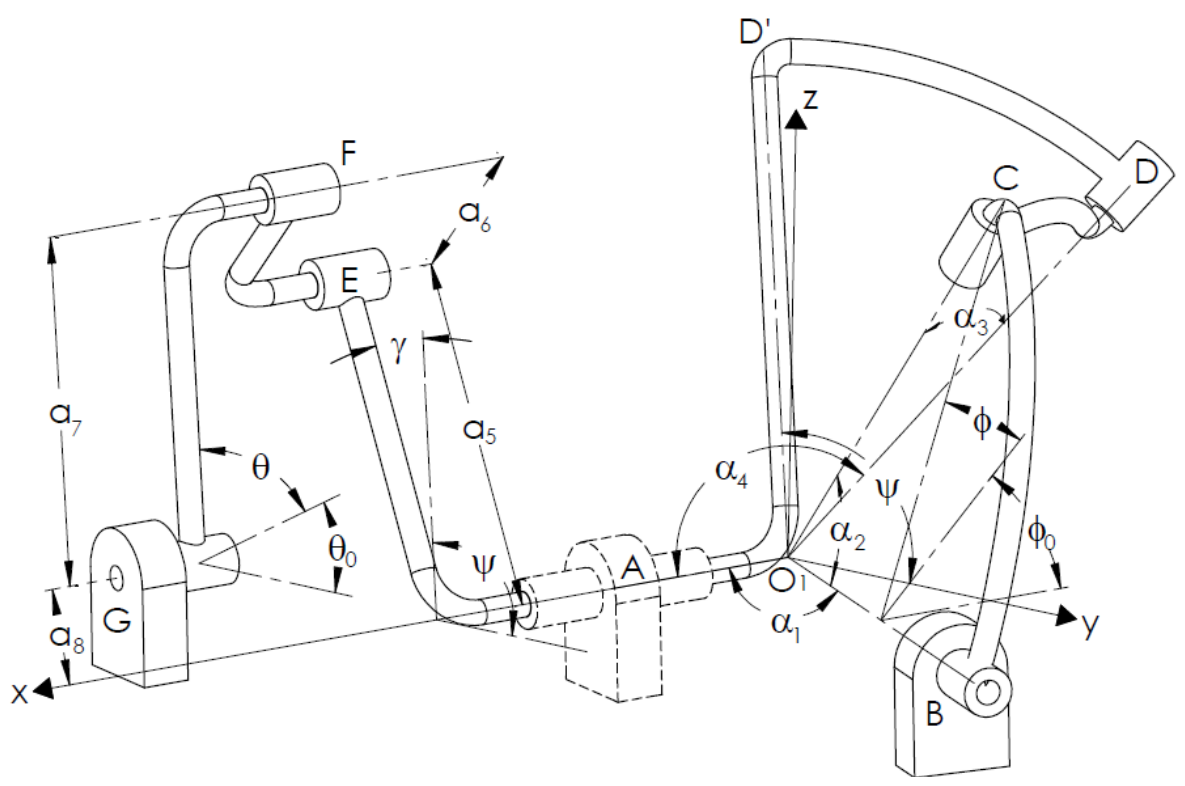

Fig. 4 Kinematic representation of the plano-spherical 6R linkage

The I/O relationship for the spherical loop is the same as for the first loop of double-spherical 6R linkage and is given by Eq. (32). All links of the planar loop move parallel to the yz-plane, so the $\mathrm{x}$ coordinates are irrelevant when analyzing this loop. Scaling all the link lengths of the planar four bar mechanism has no effect on the function synthesis task, so without loss of generality we will assume $\mathrm{a}_{5}$ $=1$. For $\gamma=0$, the I/O equation for the planar loop can be derived as (Alizade et al., 2013):

$$
1-\mathrm{a}_{6}{ }^{2}+\mathrm{a}_{7}^{2}+\mathrm{a}_{8}^{2}-2 \mathrm{a}_{8} \sin \psi-2 \mathrm{a}_{7} \cos (\psi-\theta)+2 \mathrm{a}_{7} \mathrm{a}_{8} \sin \theta=0
$$

This I/O relationship contains three construction parameters: $a_{6}, a_{7}, a_{8}$. Together with the Chebychev error L, there are four parameters to be determined. Therefore, the function synthesis may be performed for four design points. Eq. (57) can be written in the polynomial form of Eq. (8), where

$$
\mathrm{P}_{1}=\frac{1-\mathrm{a}_{6}^{2}+\mathrm{a}_{7}^{2}+\mathrm{a}_{8}^{2}}{2 \mathrm{a}_{7} \mathrm{a}_{8}}, \mathrm{f}_{1}\left(\mathbf{x}_{\mathrm{i}}\right)=1, \mathrm{P}_{2}=\frac{1}{\mathrm{a}_{7}}, \mathrm{f}_{2}\left(\mathbf{x}_{\mathrm{i}}\right)=-\sin \psi_{\mathrm{i}}, \mathrm{P}_{3}=\frac{1}{\mathrm{a}_{8}}, \mathrm{f}_{3}\left(\mathbf{x}_{\mathrm{i}}\right)=-\cos \left(\psi_{\mathrm{i}}-\theta_{\mathrm{i}}\right), \mathrm{F}\left(\mathbf{x}_{\mathrm{i}}\right)=-\sin \theta_{\mathrm{i}}
$$

$\mathrm{P}_{\mathrm{j}}$ are solved linearly from Eq. (8) using the Remez algorithm and then the construction parameters are solved from Eq. (58) as follows: 


$$
\mathrm{a}_{7}=\frac{1}{\mathrm{P}_{2}}, \mathrm{a}_{8}=\frac{1}{\mathrm{P}_{3}}, \mathrm{a}_{6}=\sqrt{1+\mathrm{a}_{7}^{2}+\mathrm{a}_{8}^{2}-2 \mathrm{P}_{1} \mathrm{a}_{7} \mathrm{a}_{8}}
$$

\subsection{Plano-Spherical 6R Mechanism with 8, 9 and 10 Parameters}

When we include the twist angle $\gamma$ to the planar loop Eq. (57) becomes

$$
\begin{aligned}
1-\mathrm{a}_{6}{ }^{2}+\mathrm{a}_{7}{ }^{2}+\mathrm{a}_{8}{ }^{2} & -2 \mathrm{a}_{8} \cos \gamma \sin \psi-2 \mathrm{a}_{8} \sin \gamma \cos \psi-2 \mathrm{a}_{7} \cos \gamma \cos (\psi-\theta) \\
+ & 2 \mathrm{a}_{7} \sin \gamma \sin (\psi-\theta)+2 \mathrm{a}_{7} \mathrm{a}_{8} \sin \theta=0
\end{aligned}
$$

Eq. (60) can be written in polynomial form in Eq. (15) where

$$
\begin{gathered}
\mathrm{P}_{1}=\frac{1-\mathrm{a}_{6}^{2}+\mathrm{a}_{7}^{2}+\mathrm{a}_{8}^{2}}{2 \mathrm{a}_{7} \mathrm{a}_{8}}, \mathrm{f}_{1}\left(\mathbf{x}_{\mathrm{i}}\right)=1, \mathrm{P}_{2}=\frac{\cos \gamma}{\mathrm{a}_{7}}, \mathrm{f}_{2}\left(\mathbf{x}_{\mathrm{i}}\right)=-\sin \psi_{\mathrm{i}}, \mathrm{P}_{3}=\frac{\sin \gamma}{\mathrm{a}_{7}}, \mathrm{f}_{3}\left(\mathbf{x}_{\mathrm{i}}\right)=-\cos \psi_{\mathrm{i}}, \mathrm{P}_{4}=\frac{\cos \gamma}{\mathrm{a}_{8}}, \\
\mathrm{f}_{4}\left(\mathbf{x}_{\mathrm{i}}\right)=-\cos \left(\psi_{\mathrm{i}}-\theta_{\mathrm{i}}\right), \mathrm{P}_{5}=\frac{\sin \gamma}{\mathrm{a}_{8}}, \mathrm{f}_{5}\left(\mathbf{x}_{\mathbf{i}}\right)=\sin \left(\psi_{\mathrm{i}}-\theta_{\mathrm{i}}\right), \mathrm{F}\left(\mathbf{x}_{\mathbf{i}}\right)=-\sin \theta_{\mathrm{i}}
\end{gathered}
$$

The dependency in between $P_{j}$ is the same as Eq. (17). We assign $P_{5}=\lambda, P_{j}=\ell_{j} \lambda+m_{j}$ for $j=1, \ldots, 4$ and $\mathrm{L}=\ell \lambda+\mathrm{m}$. After finding $\ell_{\mathrm{j}}$ and $\mathrm{m}_{\mathrm{j}}$ as explained in Section $2, \lambda$ is determined as in Eq. (18). The construction parameters are determined as

$$
\gamma=\operatorname{atan} 2\left(\mathrm{P}_{2}, \mathrm{P}_{3}\right), \mathrm{a}_{7}=\frac{\cos \gamma}{\mathrm{P}_{2}}, \mathrm{a}_{8}=\frac{\cos \gamma}{\mathrm{P}_{4}}, \mathrm{a}_{6}=\sqrt{1+\mathrm{a}_{7}^{2}+\mathrm{a}_{8}^{2}-\mathrm{P}_{1} 2 \mathrm{a}_{7} \mathrm{a}_{8}}
$$

When we use $\theta_{0}+\theta$ instead of $\theta$ in Eq. (57), we obtain

$$
\begin{gathered}
1-\mathrm{a}_{6}{ }^{2}+\mathrm{a}_{7}{ }^{2}+\mathrm{a}_{8}{ }^{2}-2 \mathrm{a}_{8} \sin \psi-2 \mathrm{a}_{7} \cos \theta_{0} \cos (\psi-\theta)-2 \mathrm{a}_{7} \sin \theta_{0} \sin (\psi-\theta) \\
+2 \mathrm{a}_{7} \mathrm{a}_{8} \sin \theta_{0} \cos \theta+2 \mathrm{a}_{7} \mathrm{a}_{8} \cos \theta_{0} \sin \theta=0
\end{gathered}
$$

Eq. (60) can be written in polynomial form in Eq. (15) where

$$
\begin{gathered}
\mathrm{P}_{1}=\frac{1-\mathrm{a}_{6}^{2}+\mathrm{a}_{7}^{2}+\mathrm{a}_{8}^{2}}{2 \mathrm{a}_{7} \mathrm{a}_{8} \cos \theta_{0}}, \mathrm{f}_{1}\left(\mathbf{x}_{\mathrm{i}}\right)=1, \mathrm{P}_{2}=\frac{1}{\mathrm{a}_{7} \cos \theta_{0}}, \mathrm{f}_{2}\left(\mathbf{x}_{\mathbf{i}}\right)=-\sin \psi_{\mathrm{i}}, \mathrm{P}_{3}=\tan \theta_{0}, \mathrm{f}_{3}\left(\mathbf{x}_{\mathrm{i}}\right)=\cos \theta_{\mathrm{i}}, \mathrm{P}_{4}=\frac{1}{\mathrm{a}_{8}}, \\
\mathrm{f}_{4}\left(\mathbf{x}_{\mathbf{i}}\right)=-\cos \left(\psi_{\mathrm{i}}-\theta_{\mathrm{i}}\right), \mathrm{P}_{5}=\frac{\tan \theta_{0}}{\mathrm{a}_{8}}, \mathrm{f}_{5}\left(\mathbf{x}_{\mathbf{i}}\right)=-\sin \left(\psi_{\mathrm{i}}-\theta_{\mathrm{i}}\right), \mathrm{F}\left(\mathbf{x}_{\mathbf{i}}\right)=-\sin \theta_{\mathrm{i}}
\end{gathered}
$$

The dependency in between $P_{j}$ is the same as Eq. (22). We assign $P_{5}=\lambda, P_{j}=\ell_{j} \lambda+m_{j}$ for $j=1, \ldots, 4$ and $\mathrm{L}=\ell \lambda+\mathrm{m}$. After finding $\ell_{\mathrm{j}}$ and $\mathrm{m}_{\mathrm{j}}$ as explained in Section $2, \lambda$ is determined as in Eq. (23). The construction parameters are determined as

$$
\theta_{0}=\left\{\begin{array}{cc}
\tan ^{-1} \mathrm{P}_{3} & \text { if } \mathrm{P}_{2}>0 \\
\tan ^{-1} \mathrm{P}_{3}+\pi & \text { if } \mathrm{P}_{2}<0
\end{array}, \mathrm{a}_{8}=\frac{1}{\mathrm{P}_{4}}, \mathrm{a}_{7}=\frac{1}{\mathrm{P}_{2} \cos \theta_{0}}, \mathrm{a}_{6}=\sqrt{1+\mathrm{a}_{7}{ }^{2}+\mathrm{a}_{8}{ }^{2}-2 \mathrm{P}_{1} \mathrm{a}_{7} \mathrm{a}_{8} \cos \theta_{0}}\right.
$$

Finally we can add both of $\gamma$ and $\theta_{0}$ to Eq. (57) to obtain 


$$
\begin{gathered}
1-a_{6}^{2}+a_{7}^{2}+a_{8}^{2}-2 a_{8} \cos \gamma \sin \psi-2 a_{8} \sin \gamma \cos \psi-2 a_{7} \cos \left(\gamma-\theta_{0}\right) \cos (\psi-\theta) \\
+2 a_{7} \sin \left(\gamma-\theta_{0}\right) \sin (\psi-\theta)+2 a_{7} a_{8} \sin \theta_{0} \cos \theta+2 a_{7} a_{8} \cos \theta_{0} \sin \theta=0
\end{gathered}
$$

Eq. (66) can be written in polynomial form in Eq. (29) where

$$
\begin{gathered}
\mathrm{P}_{1}=\frac{1-\mathrm{a}_{6}^{2}+\mathrm{a}_{7}^{2}+\mathrm{a}_{8}^{2}}{2 \mathrm{a}_{7} \mathrm{a}_{8} \cos \theta_{0}}, \mathrm{f}_{1}\left(\mathbf{x}_{\mathbf{i}}\right)=1, \mathrm{P}_{2}=\frac{\cos \gamma}{\mathrm{a}_{7} \cos \theta_{0}}, \mathrm{f}_{2}\left(\mathbf{x}_{\mathbf{i}}\right)=-\sin \psi_{\mathrm{i}}, \mathrm{P}_{3}=\tan \theta_{0}, \mathrm{f}_{3}\left(\mathbf{x}_{\mathbf{i}}\right)=\cos \theta_{\mathrm{i}}, \mathrm{P}_{4}=\frac{\sin \gamma}{\mathrm{a}_{7} \cos \theta_{0}}, \\
\mathrm{f}_{4}\left(\mathbf{x}_{\mathbf{i}}\right)=-\cos \psi_{\mathrm{i}}, \mathrm{P}_{5}=\frac{\cos \left(\gamma-\theta_{0}\right)}{\mathrm{a}_{8} \cos \theta_{0}}, \mathrm{f}_{5}\left(\mathbf{x}_{\mathbf{i}}\right)=-\cos \left(\psi_{\mathrm{i}}-\theta_{\mathrm{i}}\right), \mathrm{P}_{6}=\frac{\sin \left(\gamma-\theta_{0}\right)}{\mathrm{a}_{8} \cos \theta_{0}}, \mathrm{f}_{6}\left(\mathbf{x}_{\mathbf{i}}\right)=\sin \left(\psi_{\mathrm{i}}-\theta_{\mathrm{i}}\right), \mathrm{F}\left(\mathbf{x}_{\mathbf{i}}\right)=-\sin \theta_{\mathrm{i}}
\end{gathered}
$$

There are five construction parameters, whereas there are six $P_{j}$. The relationship between $P_{j}$ can be found to be

$$
\mathrm{P}_{3}\left(\mathrm{P}_{2} \mathrm{P}_{5}+\mathrm{P}_{4} \mathrm{P}_{6}\right)=\mathrm{P}_{4} \mathrm{P}_{5}-\mathrm{P}_{2} \mathrm{P}_{6}
$$

Let $\mathrm{P}_{6}=\lambda, \mathrm{P}_{\mathrm{j}}=\ell_{\mathrm{j}} \lambda+\mathrm{m}_{\mathrm{j}}$ for $\mathrm{j}=1, \ldots, 5$ and $\mathrm{L}=\ell \lambda+\mathrm{m} . \ell_{\mathrm{j}}$ and $\mathrm{m}_{\mathrm{j}}$ can be solved linearly as explained in Section 2. Eq. (68) is a cubic equation in terms of $\lambda$ and can be solved analytically. The construction parameters are solved from Eq. (67) as

$$
\theta_{0}=\tan ^{-1} P_{3}, \gamma=\operatorname{atan} 2\left(P_{2} \cos \theta_{0}, P_{4} \cos \theta_{0}\right), a_{7}=\frac{\cos \gamma}{P_{2} \cos \theta_{0}}, a_{8}=\frac{\cos \left(\gamma-\theta_{0}\right)}{P_{5} \cos \theta_{0}}, a_{6}=\sqrt{1+a_{7}^{2}+a_{8}^{2}-2 P_{1} a_{7} a_{8} \cos \theta_{0}}
$$

\section{The Function Synthesis Problem}

Let the function to be generated be $\mathrm{z}=\mathrm{f}(\mathrm{x})$ for $\mathrm{x}_{\min } \leq \mathrm{x} \leq \mathrm{x}_{\max }$ and $\mathrm{z}_{\min } \leq \mathrm{z} \leq \mathrm{z}_{\max }$. The independent variable $\mathrm{x}$ should be related to the mechanism input $\phi$ and the dependent variable $\mathrm{z}$ should be related to the mechanism output $\theta$. However, since we are making use of the method of decomposition, we have an intermediate joint variable $\psi$ for the double-spherical and plano-spherical mechanisms and $\mathrm{s}$ for the double-planar mechanism. We shall introduce $y=g(x)$ for $y_{\min } \leq y \leq y_{\max }$ such that $\mathrm{z}=\mathrm{h}(\mathrm{y})$ and hence $f(x)=h(g(x))$. Depending on the application some or all of $z=f(x), x_{\min }, x_{\max }, z_{\min }$ and $z_{\max }$ may be demanded by the specific task. However, the designer can freely select $y=g(x), y_{\min }$ and $y_{\max }$. The design may be enhanced via different selection of the function $g$ and also the boundaries of $y$.

We shall linearly relate $\mathrm{x}$ to $\phi, \mathrm{y}$ to $\psi$ (or s) and $\mathrm{z}$ to $\theta$ as

$$
\frac{\mathrm{x}-\mathrm{x}_{\min }}{\mathrm{x}_{\max }-\mathrm{x}_{\min }}=\frac{\phi-\phi_{\min }}{\phi_{\max }-\phi_{\min }}, \frac{\mathrm{y}-\mathrm{y}_{\min }}{\mathrm{y}_{\max }-\mathrm{y}_{\min }}=\frac{\psi-\psi_{\min }}{\psi_{\text {max }}-\psi_{\min }}, \frac{\mathrm{z}-\mathrm{z}_{\min }}{\mathrm{z}_{\max }-\mathrm{z}_{\min }}=\frac{\theta-\theta_{\min }}{\theta_{\max }-\theta_{\min }}
$$

Then desired $\psi$ and $\theta$ values for given input $\phi$ are found as follows:

$$
\phi=\frac{\phi_{\text {max }}-\phi_{\text {min }}}{\mathrm{x}_{\text {max }}-\mathrm{x}_{\text {min }}}\left(\mathrm{x}-\mathrm{x}_{\text {min }}\right)+\phi_{\min }, \psi=\frac{\psi_{\text {max }}-\psi_{\min }}{\mathrm{y}_{\text {max }}-\mathrm{y}_{\text {min }}}\left(\mathrm{g}(\mathrm{x})-\mathrm{y}_{\text {min }}\right)+\psi_{\min }, \theta=\frac{\theta_{\text {max }}-\theta_{\text {min }}}{\mathrm{z}_{\text {max }}-\mathrm{z}_{\text {min }}}\left(\mathrm{f}(\mathrm{x})-\mathrm{z}_{\text {min }}\right)+\theta_{\text {min }}
$$

and conversely

$$
\mathrm{x}=\frac{\mathrm{x}_{\max }-\mathrm{x}_{\min }}{\phi_{\max }-\phi_{\min }}\left(\phi-\phi_{\min }\right)+\mathrm{x}_{\min }, \mathrm{y}=\frac{\mathrm{y}_{\max }-\mathrm{y}_{\min }}{\psi_{\text {max }}-\psi_{\min }}\left(\psi-\psi_{\min }\right)+\mathrm{y}_{\min }, \mathrm{z}=\frac{\mathrm{z}_{\max }-\mathrm{z}_{\min }}{\theta_{\text {max }}-\theta_{\text {min }}}\left(\theta-\theta_{\min }\right)+\mathrm{z}_{\text {min }}
$$


We make use of Eq. (71) when determining the design points $\left\{\phi_{\mathrm{i}}\right\}_{1}^{\mathrm{n}},\left\{\psi_{\mathrm{i}}\right\}_{1}^{\mathrm{n}}$ and $\left\{\theta_{\mathrm{i}}\right\}_{1}^{\mathrm{n}}$ from $\left\{\mathrm{x}_{\mathrm{i}}\right\}_{1}^{\mathrm{n}}$, $\left\{\mathrm{y}_{\mathrm{i}}\right\}_{1}^{\mathrm{n}}=\left\{\mathrm{g}\left(\mathrm{x}_{\mathrm{i}}\right)\right\}_{1}^{\mathrm{n}}$ and $\left\{\mathrm{z}_{\mathrm{i}}\right\}_{1}^{\mathrm{n}}=\left\{\mathrm{f}\left(\mathrm{x}_{\mathrm{i}}\right)\right\}_{1}^{\mathrm{n}}$. Selection of $\left\{\mathrm{x}_{\mathrm{i}}\right\}_{1}^{\mathrm{n}}$ may be done with equal spacing, Chebyshev spacing, or any other type of spacing depending of the application. Our experience is that the Remez algorithm converges faster (in 3 or 4 iterations) when the initial spacing is selected as the Chebyshev spacing.

We make use of Eq. (72) after the synthesis is done and we need to check the error in between the desired $z=f(x)$ and the generated $z$ with the mechanism. At this step, one shall determine the output values of the mechanism loops for several given input values, say 100 values, by solving the $\mathrm{I} / \mathrm{O}$ relationship.

\section{Numerical examples}

We have implemented all the formulations in the previous sections in Microsoft Excel ${ }^{\circledR}$ and performed several different function synthesis tasks. Here we present some of the results for illustration.

First, we work on power functions of type $z=x^{a}$. As an example, consider $z=x^{0.5}$ for $1 \leq x \leq 5$, which is decomposed as $y=x^{0.6}, z=y^{5 / 6}$. For $130^{\circ} \geq \phi \geq 50^{\circ}$ input range and $210^{\circ} \leq \theta \leq 270^{\circ}$ output range, we performed synthesis for all of the double-planar, double-spherical and plano-spherical 6-R linkages with no extra parameters $\phi_{0}, \theta_{0}$, etc. in order to compare the resultant error. The intermediate joint variable limits are chosen as $0.3 \leq \mathrm{s} \leq 0.9$ for the double-planar linkage and $110^{\circ} \leq \psi \leq 200^{\circ}$ for the double-spherical and the plano-spherical linkages. The initial design points in between the limits are determined using Chebyshev spacing. The percentage error variation in the $\mathrm{z}$ values defined as

$$
\% \text { Error }=\frac{\mathrm{z}_{\text {desired }}-\mathrm{z}_{\text {mechanism }}}{\mathrm{Z}_{\text {desired }}} \times 100
$$

is given in Fig. 5. As seen from Fig. 5, the lowest percentage error values are obtained with the doublespherical linkage. The maximum error magnitude is $0.123 \%$ for the double-spherical linkage, $0.291 \%$ for the plano-spherical linkage and $1.54 \%$ for the double-planar linkage. So, for $\mathrm{z}=\mathrm{x}^{0.5}$ it seems like the double-spherical linkage provides the best approximation. Of course it is possible to change the intermediate function $\mathrm{y}=\mathrm{f}(\mathrm{x})$ and the boundaries for the input, output and intermediate joint variables. For different selections, some other linkage may be better than the others. Similarly, the designer may test several different mechanisms for the same function in order to determine the best-suited mechanism for that specific function.

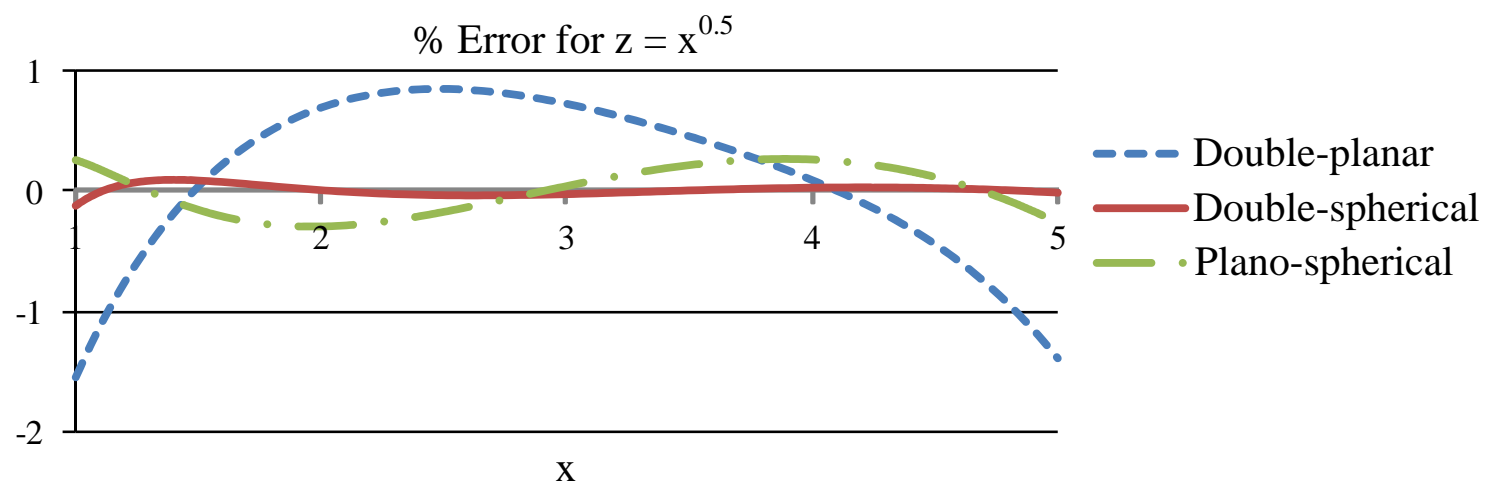

Fig. 5 Percentage error variations for $z=x^{0.5}$ 
It is important to note that not every function can be generated with all of the Bennett linkages for arbitrary selections of the joint variable limits. In the above example, we found a proper set of joint variable limits so that the synthesis can be performed for all of the three linkages. If one is to work on just one of the linkages for a specific function, it is possible to decrease the maximum error to the levels of $0.01 \%$. For example, using a double-spherical 6R linkage, for the same function as above, i.e. for $\mathrm{z}=\mathrm{x}^{0.5}$ for $1 \leq \mathrm{x} \leq 5$, if we select $\mathrm{y}(\mathrm{x})=\mathrm{x}^{0.8}, 126^{\circ} \geq \phi \geq 59^{\circ}, 193^{\circ} \leq \theta \leq 260^{\circ}$ and $94^{\circ} \leq \psi \leq 199^{\circ}$, the maximum absolute error is as low as $0.0074 \%$.

The second function we worked on is the $\sin (\mathrm{x})$ function for $45^{\circ} \leq \mathrm{x} \leq 60^{\circ}$, which is decomposed as $\mathrm{y}=$ $\tan (x / 2)$ and $z=2 y /\left(1+y^{2}\right)$. The reason we have such a short range for $x$ is the constraint that we want to compare the three linkages for the same function and same joint variable limits. In this case, we employed the extra parameters $\phi_{0}$ and $\theta_{0}$ for the input and output angles, respectively. We used the same joint variable limits as above: $130^{\circ} \geq \phi \geq 50^{\circ}, 210^{\circ} \leq \theta \leq 270^{\circ}, 0.6 \leq \mathrm{s} \leq 0.9$ and $110^{\circ} \leq \psi \leq 200^{\circ}$. In this case, the error values for the three mechanisms are very low and we do not need to present the error variation graph. The maximum error magnitude is $9.3 \times 10^{-4} \%$ for the double-spherical linkage, $9.2 \times 10^{-3} \%$ for the plano-spherical linkage and $0.042 \%$ for the double-planar linkage. As expected, as the number of design points increases, the accuracy of approximation increases. The construction parameters designed for the function generation of $\mathrm{z}=\mathrm{x}^{0.5}$ and $\mathrm{z}=\sin (\mathrm{x})$ are listed in Table 1. Note that some link lengths for the plano-spherical linkage turn out to be negative. This does not mean that the construction of the mechanism is not possible. Referring to Fig. 4, $\mathrm{a}_{8}$ is a directed dimension, so it can be negative, anyway. On the other hand, a ${ }_{7}$ being computed negative means that the angle of this link should not be measured from $+y$ direction to GF direction as in Fig. 4, but in the opposite direction. Practically this does not cause any problems. One can simply extend this link and get the measurement from the extension.

Table 1. Designed construction parameters for generation of $z=x^{0.5}$ and $z=\sin (x)$

\begin{tabular}{|c|c|c|c|c|c|}
\hline Linkage & Function & $\phi_{0}$ & $\theta_{0}$ & Link lengths & $\mid \%$ Error $\left.\right|_{\max }$ \\
\hline $\begin{array}{c}\text { Double- } \\
\text { planar }\end{array}$ & $\mathrm{z}=\mathrm{x}^{0.5}$ & - & - & $\begin{array}{c}\mathrm{a}=0.45044, \mathrm{~b}=0.6757, \mathrm{c}=0.65565, \\
\mathrm{~d}=0.32562, \mathrm{e}=0.575, \mathrm{f}=0.23706, \mathrm{~g}=1\end{array}$ & $1.54 \%$ \\
\hline $\begin{array}{c}\text { Double- } \\
\text { spherical }\end{array}$ & $\mathrm{z}=\mathrm{x}^{0.5}$ & - & - & $\begin{array}{c}\alpha_{1}=158.40^{\circ}, \alpha_{2}=129.13^{\circ}, \alpha_{3}=65.34^{\circ}, \alpha_{4}=94.45^{\circ}, \\
\alpha_{5}=150.67^{\circ}, \alpha_{6}=82.36^{\circ}, \alpha_{7}=93.03^{\circ}, \alpha_{8}=159.25^{\circ}\end{array}$ & $0.123 \%$ \\
\hline $\begin{array}{c}\text { Plano- } \\
\text { spherical }\end{array}$ & $\mathrm{z}=\mathrm{x}^{0.5}$ & - & - & $\begin{array}{c}\alpha_{1}=158.40^{\circ}, \alpha_{2}=129.13^{\circ}, \alpha_{3}=65.34^{\circ}, \alpha_{4}=94.45^{\circ}, \\
\mathrm{a}_{5}=1, \mathrm{a}_{6}=1.1770, \mathrm{a}_{7}=-0.5488, \mathrm{a}_{8}=-0.1790\end{array}$ & $0.291 \%$ \\
\hline $\begin{array}{c}\text { Double- } \\
\text { spherical }\end{array}$ & $\mathrm{z}=\mathrm{x}^{0.5}$ & - & - & $\begin{array}{c}\alpha_{1}=156.20^{\circ}, \alpha_{2}=274.79^{\circ}, \alpha_{3}=77.03^{\circ}, \alpha_{4}=323.18^{\circ}, \\
\alpha_{5}=351.84^{\circ}, \alpha_{6}=93.15^{\circ}, \alpha_{7}=279.21^{\circ}, \alpha_{8}=172.37^{\circ}\end{array}$ & $0.0074 \%$ \\
\hline $\begin{array}{c}\text { Double- } \\
\text { planar }\end{array}$ & $\mathrm{z}=\sin (\mathrm{x})$ & $90.96^{\circ}$ & $-13.84^{\circ}$ & $\begin{array}{c}\mathrm{a}=0.3854, \mathrm{~b}=1.4708, \mathrm{c}=1.0943, \\
\mathrm{~d}=0.0708, \mathrm{e}=4.0310, \mathrm{f}=3.9615, \mathrm{~g}=1\end{array}$ & $0.042 \%$ \\
\hline $\begin{array}{c}\text { Double- } \\
\text { spherical }\end{array}$ & $\mathrm{z}=\sin (\mathrm{x})$ & $172.88^{\circ}$ & $43.25^{\circ}$ & $\begin{array}{c}\alpha_{1}=194.54^{\circ}, \alpha_{2}=62.24^{\circ}, \alpha_{3}=126.61^{\circ}, \alpha_{4}=51.52^{\circ}, \\
\alpha_{5}=174.46^{\circ}, \alpha_{6}=171.44^{\circ}, \alpha_{7}=172.04^{\circ}, \alpha_{8}=175.94^{\circ}\end{array}$ & $9.3 \times 10^{-4} \%$ \\
\hline $\begin{array}{c}\text { Plano- } \\
\text { spherical }\end{array}$ & $\mathrm{z}=\sin (\mathrm{x})$ & $172.88^{\circ}$ & $135.52^{\circ}$ & $\begin{array}{c}\alpha_{1}=194.54^{\circ}, \alpha_{2}=62.24^{\circ}, \alpha_{3}=126.61^{\circ}, \alpha_{4}=51.52^{\circ}, \\
\mathrm{a}_{5}=1, \mathrm{a}_{6}=1.3908, \mathrm{a}_{7}=0.4618, \mathrm{a}_{8}=-0.0899\end{array}$ & $9.2 \times 10^{-3} \%$ \\
\hline
\end{tabular}

*First three rows correspond to synthesis of different linkages for the same range of input/output variables for comparison reasons, whereas row 4 corresponds to synthesis of a double-spherical linkage for further minimized error by changing the input/output ranges.

As a further case study, we worked on a function used in Alizade and Kilit (2005) for comparison. In the paper, the authors generate $\mathrm{z}=\mathrm{x}^{0.6}$ for $1 \leq \mathrm{x} \leq 5$ by means of a spherical four-bar mechanism with 
five construction parameters: the four link lengths $\alpha_{1}, \alpha_{2}, \alpha_{3}, \alpha_{4}$ and the extra parameter $\theta_{0}$ for the output angle. They used interpolation approximation with equally spaced five precision points and the limits are selected as $8^{\circ} \leq \phi \leq 80^{\circ}, 5^{\circ} \leq \theta \leq 160^{\circ}$ for the input and the output joint variables, respectively. The variation in the percentage error is depicted in Fig. 6 . In this case, the maximum absolute percentage error is $2.229 \%$.

$\%$ Error for $\mathrm{z}=\mathrm{x}^{0.6}$ with spherical $4 \mathrm{R}$ mechanism - interpolation approximation

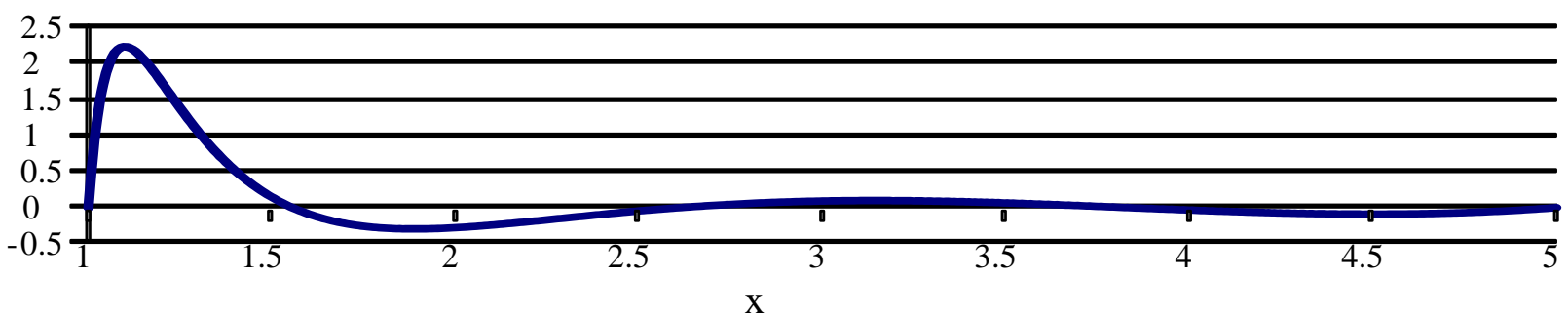

Fig. 6 Percentage error variation for $\mathrm{z}=\mathrm{x}^{0.6}$ for spherical four-bar mechanism with interpolation approximation

When we use Chebyshev approximation for the same function $\mathrm{z}=\mathrm{x}^{0.6}$ for $1 \leq \mathrm{x} \leq 5$ with the spherical four-bar mechanism with same joint variable limits and five construction parameters, relatively lower error values are obtained as shown in Fig. 7. In this case, the maximum absolute error is $1.28 \%$.

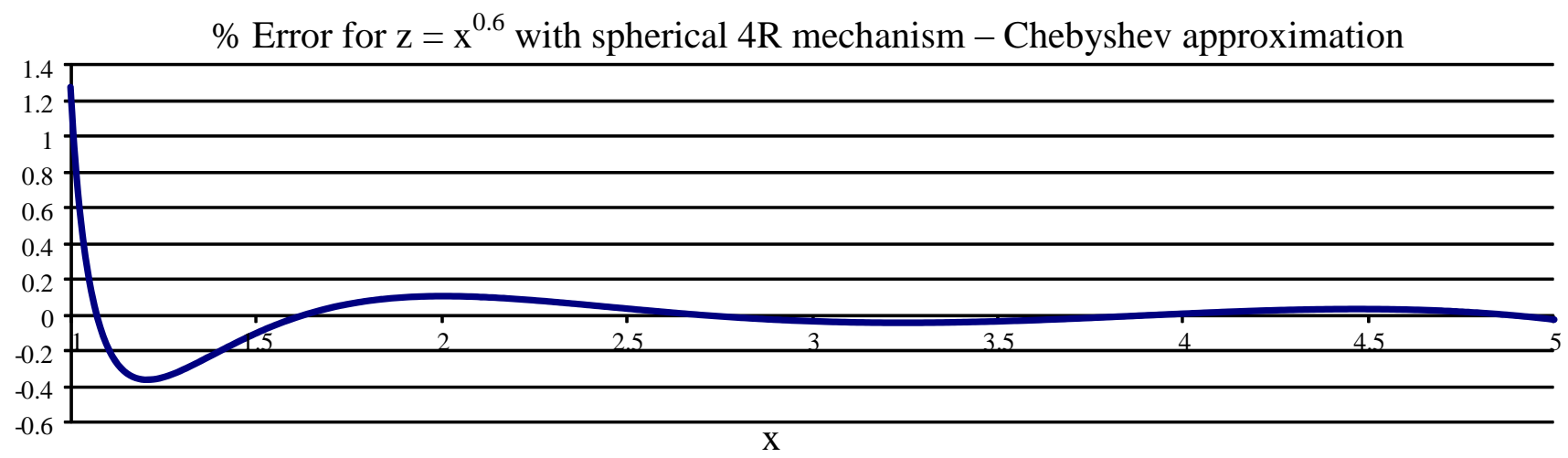

Fig. 7 Percentage error variation for $\mathrm{z}=\mathrm{x}^{0.6}$ for spherical four-bar mechanism with Chebyshev approximation

When we apply the Chebyshev approximation with the double spherical mechanism for the same function with the same input-output joint limits and choose $y=x^{0.75}$ and $75^{\circ} \leq \psi \leq 160^{\circ}$, the error variation in Fig. 8 is obtained. The maximum absolute error is $0.016 \%$. 
$\%$ Error for $\mathrm{z}=\mathrm{x}^{0.6}$ with double-spherical $6 \mathrm{R}$ mechanism

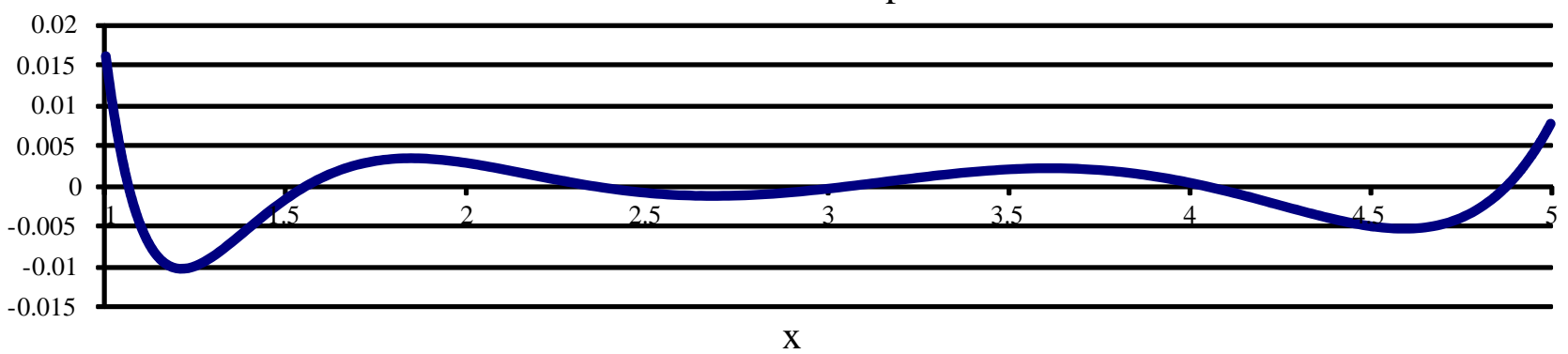

Fig. 8 Percentage error variation for $z=x^{0.6}$ for double-spherical $6 \mathrm{R}$ mechanism with Chebyshev approximation

The designed construction parameters for the spherical four-bar and double-spherical 6R linkages are listed in Table 2.

Table 2. Designed construction parameters for generation of $\mathrm{z}=\mathrm{x}^{0.6}$

\begin{tabular}{|c|c|c|c|c|c|}
\hline Linkage & Approximation & $\phi_{0}$ & $\theta_{0}$ & Link lengths & Error $\left.\right|_{\max }$ \\
\hline Spherical 4R & Interpolation & - & $11.03^{\circ}$ & $\alpha_{1}=10.75^{\circ}, \alpha_{2}=294.90^{\circ}, \alpha_{3}=30.46^{\circ}, \alpha_{4}=270.47^{\circ}$ & $2.23 \%$ \\
\hline Spherical 4R & Chebyshev & - & $9.96^{\circ}$ & $\alpha_{1}=271.92^{\circ}, \alpha_{2}=87.00^{\circ}, \alpha_{3}=34.01^{\circ}, \alpha_{4}=142.30^{\circ}$ & $1.28 \%$ \\
\hline $\begin{array}{c}\text { Double- } \\
\text { spherical }\end{array}$ & Chebyshev & $52^{\circ}$ & $-4.91^{\circ}$ & $\begin{array}{c}\alpha_{1}=10.75^{\circ}, \alpha_{2}=114.9^{\circ}, \alpha_{3}=28.34^{\circ}, \alpha_{4}=93.17^{\circ}, \\
\alpha_{5}=337.74^{\circ}, \alpha_{6}=203.92^{\circ}, \alpha_{7}=355.24^{\circ}, \alpha_{8}=185.03^{\circ}\end{array}$ & $0.016 \%$ \\
\hline
\end{tabular}

As a final case study, we demonstrate design of the same type of linkage for three different types of functions: $\mathrm{z}=\mathrm{x}^{\mathrm{a}}, \mathrm{z}=\mathrm{a}^{\mathrm{x}}$ and $\mathrm{z}=\sin (\mathrm{x})$. The worked-out functions are $\mathrm{z}=\mathrm{x}^{0.5}$ for $1 \leq \mathrm{x} \leq 5, \mathrm{z}=2^{\mathrm{x}}$ for $\pi / 4 \leq x \leq 2 \pi / 3$, and $z=\sin (x)$ for $-1 \leq x \leq 1$. The variations of these functions in their respective ranges are illustrated in Fig. 9 in order to demonstrate the behavior of the functions to be generated.

$$
\mathrm{z}=\mathrm{x}^{0.5} \text { for } 1 \leq \mathrm{x} \leq 5
$$

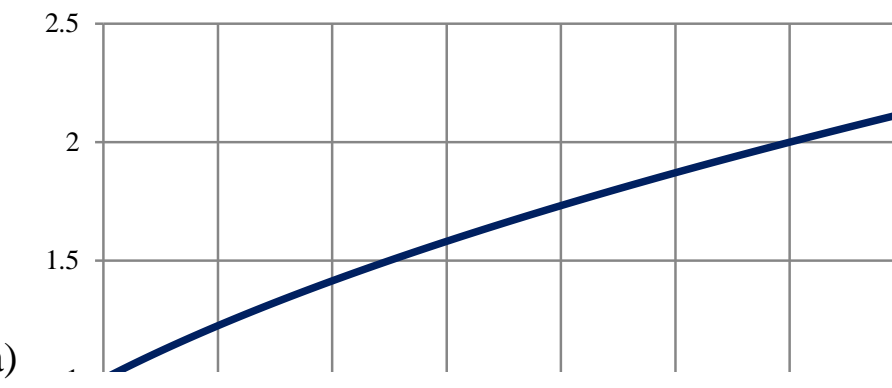

$$
\mathrm{z}=2^{\mathrm{x}} \text { for }-1 \leq \mathrm{x} \leq 1
$$

b)

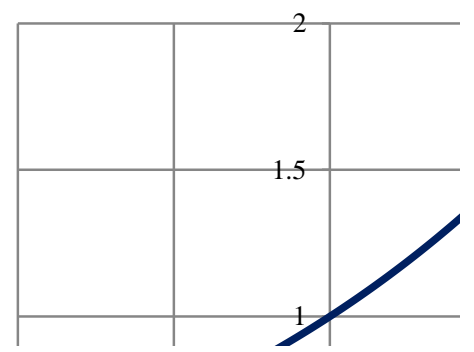


c)

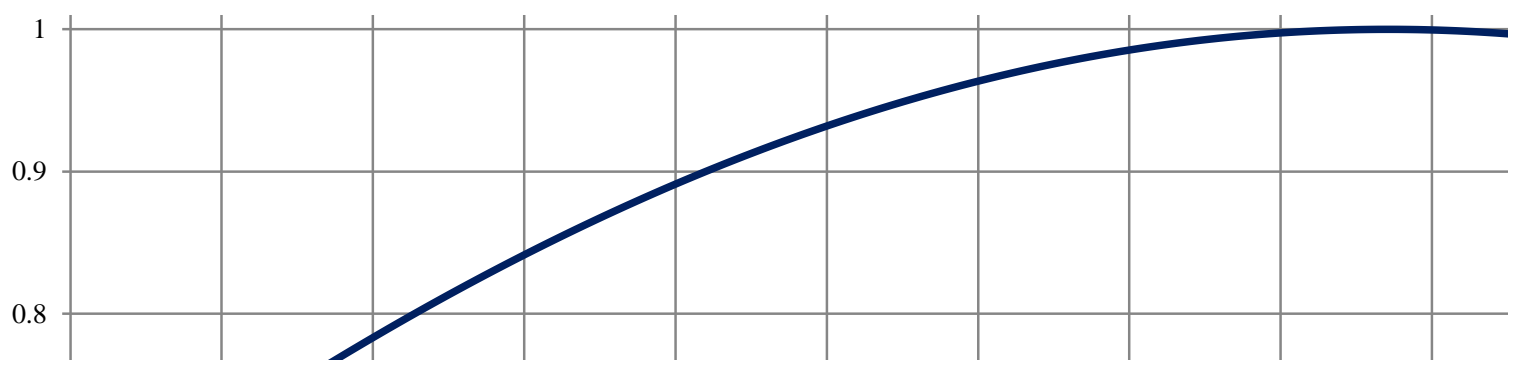

Fig. 9 a) $z=x^{0.5}$ for $1 \leq x \leq 5$, b) $z=2^{x}$ for $-1 \leq x \leq 1$ and c) $z=\sin (x)$ for $\pi / 4 \leq x \leq 2 \pi / 3$

A double-spherical 6R linkage with 8 construction parameters is designed for each of the three functions. For the function $\mathrm{z}=\mathrm{x}^{0.5}$ for $1 \leq \mathrm{x} \leq 5$, we repeat the solution above with $\mathrm{y}(\mathrm{x})=\mathrm{x}^{0.8}, 126^{\circ} \geq$ $\phi \geq 59^{\circ}, 193^{\circ} \leq \theta \leq 260^{\circ}$ and $94^{\circ} \leq \psi \leq 199^{\circ}$. The maximum absolute percentage error is as low as $0.0074 \%$. For the function $\mathrm{z}=2^{\mathrm{x}}$ for $-1 \leq \mathrm{x} \leq 1$ we found a good design with $\mathrm{y}=\mathrm{e}^{\mathrm{x}}, 30^{\circ} \leq \phi \leq 92^{\circ}, 34^{\circ}$ $\leq \theta \leq 82^{\circ}$ and $210^{\circ} \leq \psi \leq 249^{\circ}$. In this case, the maximum absolute percentage error is about $0.65 \%$. For the function $\mathrm{z}=\sin (\mathrm{x})$ for $\pi / 4 \leq \mathrm{x} \leq 2 \pi / 3$ we chose $\mathrm{y}=\tan (\mathrm{x} / 2), 81^{\circ} \leq \phi \leq 165^{\circ}, 59^{\circ} \leq \theta \leq 86.26^{\circ}$, and $219^{\circ} \leq \psi \leq 339^{\circ}$. The maximum absolute percentage error is found as $1.4 \%$. For all three functions we tried to minimize the maximum absolute percentage error. The results show that the performance of the function generator mechanism is highly dependent on the behavior of the function to be generated. The variation of the percentage errors in $\mathrm{z}$ for each of these functions are illustrated in Fig. 10. The designed construction parameters are given in Table 3.

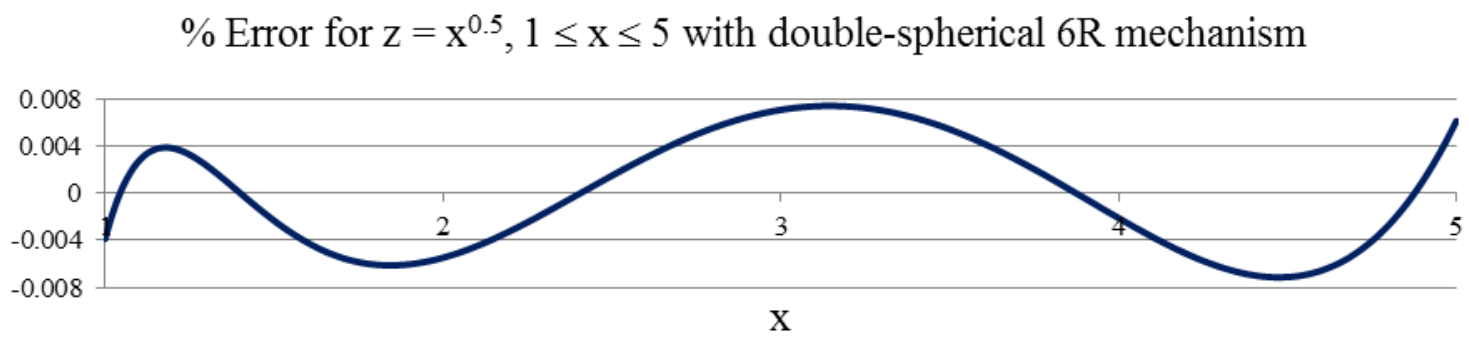

a)

$\%$ Error for $\mathrm{z}=2^{\mathrm{x}},-1 \leq \mathrm{x} \leq 1$ with double-spherical $6 \mathrm{R}$ mechanism

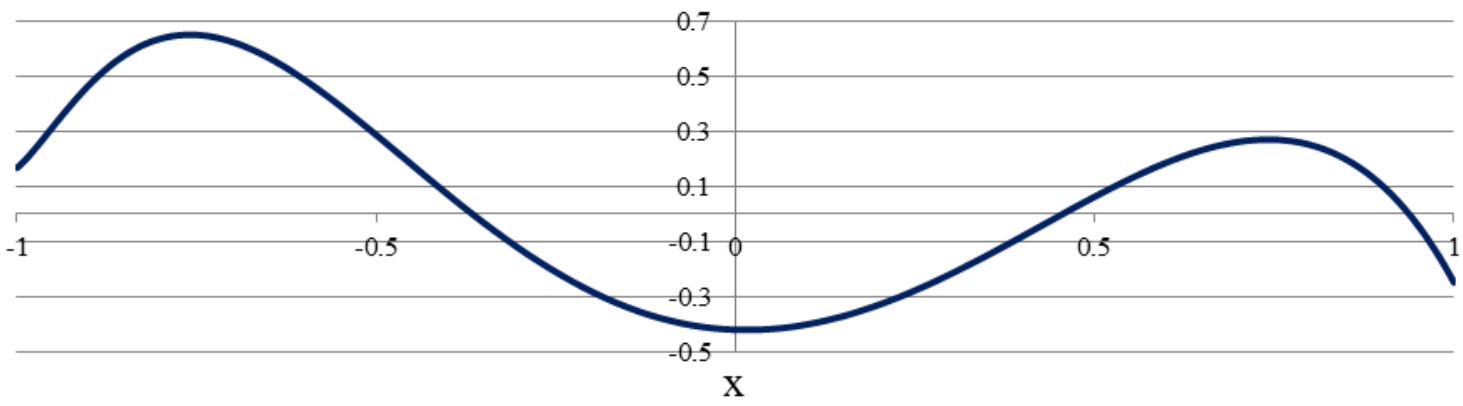

b) 
$\%$ Error for $\mathrm{z}=\sin (\mathrm{x}), 60^{\circ} \leq \mathrm{x} \leq 120^{\circ}$ with double-spherical $6 \mathrm{R}$ mechanism

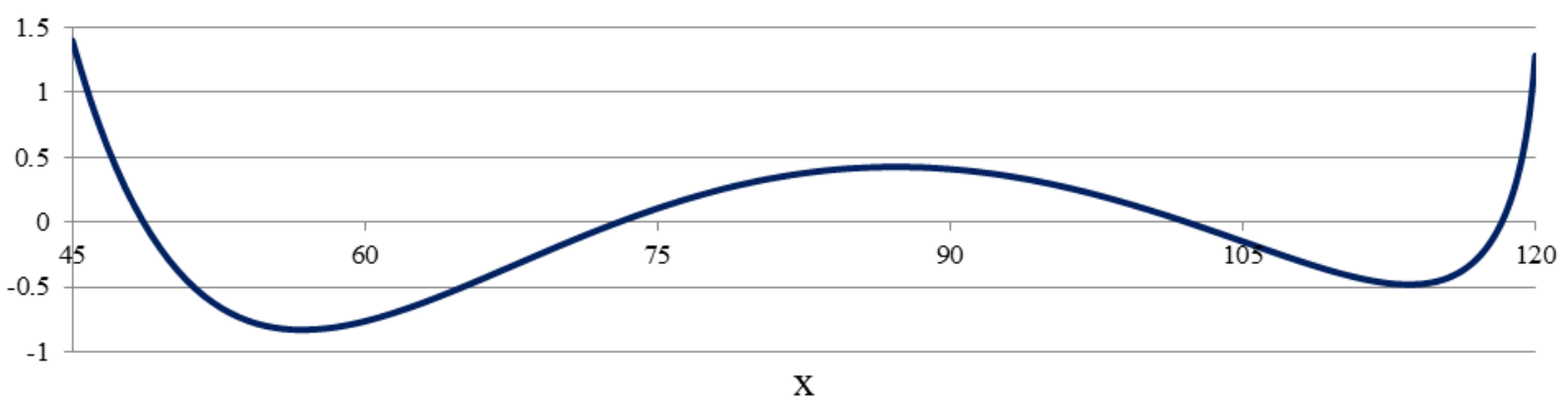

c)

Fig. 10 Percentage error variation for generation of a) $\left.\mathrm{z}=\mathrm{x}^{0.5}, 1 \leq \mathrm{x} \leq 5, \mathrm{~b}\right) \mathrm{z}=2^{\mathrm{x}},-1 \leq \mathrm{x} \leq 1$ and c) $\mathrm{z}=$ $\sin (\mathrm{x}), 45^{\circ} \leq \mathrm{x} \leq 120^{\circ}$

Table 3. Designed construction parameters for generation of $\mathrm{z}=\mathrm{x}^{0.5}, \mathrm{z}=2^{\mathrm{x}}$ and $\mathrm{z}=\sin (\mathrm{x})$

\begin{tabular}{|c|c|c|}
\hline Function & Link lengths & $\mid \%$ Error $\left.\right|_{\max }$ \\
\hline $\mathrm{z}=\mathrm{x}^{0.5}, 1 \leq \mathrm{x} \leq 5$ & $\begin{array}{c}\alpha_{1}=10.75^{\circ}, \alpha_{2}=114.9^{\circ}, \alpha_{3}=28.34^{\circ}, \alpha_{4}=93.17^{\circ}, \\
\alpha_{5}=337.74^{\circ}, \alpha_{6}=203.92^{\circ}, \alpha_{7}=355.24^{\circ}, \alpha_{8}=185.03^{\circ}\end{array}$ & $0.0074 \%$ \\
\hline $\mathrm{z}=2^{\mathrm{x}},-1 \leq \mathrm{x} \leq 1$ & $\begin{array}{c}\alpha_{1}=150.51^{\circ}, \alpha_{2}=145.82^{\circ}, \alpha_{3}=127.57^{\circ}, \alpha_{4}=14.50^{\circ}, \\
\alpha_{5}=81.62^{\circ}, \alpha_{6}=170.89^{\circ}, \alpha_{7}=75.02^{\circ}, \alpha_{8}=161.65^{\circ}\end{array}$ & $0.65 \%$ \\
\hline $\mathrm{z}=\sin (\mathrm{x}), 45^{\circ} \leq \mathrm{x} \leq 120^{\circ}$ & $\begin{array}{c}\alpha_{1}=61.49^{\circ}, \alpha_{2}=62.51^{\circ}, \alpha_{3}=64.63^{\circ}, \alpha_{4}=57.60^{\circ}, \\
\alpha_{5}=178.82^{\circ}, \alpha_{6}=76.03^{\circ}, \alpha_{7}=77.34^{\circ}, \alpha_{8}=2.21^{\circ}\end{array}$ & $1.4 \%$ \\
\hline
\end{tabular}

The construction parameter values in Tables 1-2-3 are used to construct virtual models of 6R linkages and these models are tested to satisfy the input/output joint values.

\section{Discussions and Conclusions}

The single-loop Bennett $6 \mathrm{R}$ mechanisms possess much more construction parameters than the singleloop planar four-bar, spherical four-bar or planar slider-crank mechanisms and hence, they may be used for function approximation purposes with a relatively better accuracy. The method of decomposition makes it possible for us to analytically formulate the function synthesis problem for mechanisms with so many construction parameters. The relatively easy computer implementation of the formulation enables the designer to quickly work on several alternative designs and come up with an accurate function generator mechanism.

The case studies we presented in Section 5 illustrate how a designer can compare the three types of Bennett 6R mechanisms for the same function. Also the comparison of the spherical four-bar with the double-spherical 6R mechanism clearly shows that the accuracy is improved when the 6R linkage is used for generating the same function. The last case study shows how the performance of the same type of linkage may be affected for different functions to be generated.

\section{References}


Alizade, R. I. (1994). Synthesis of four-bar spherical mechanism on five parameters. J. Mech. Eng. Russian Academy of Science (ANR), 6 (in Russian).

Alizade, R. I., Aydazade, K. P., Novruzbekov, I. G. (1980). Analysis and synthesis of planar mechanisms by using decomposition method, J. Mechanics of Machines, The Academy of Sciences of the USSR, 57, 26-32.

Alizade, R. I., Gezgin E. (2011). Synthesis of function generating spherical four bar mechanism for the six independent parameters. Mech. Mach. Theory, 46, 1316-1326.

Alizade, R. I., Kilit, Ö. (2005). Analytic synthesis of function generating spherical four-bar mechanism for the five precision points. Mech. Mach. Theory, 40(7), 863-878.

Alizade, R. I., Kiper, G., Dede, M. İ. C., Uzunoğlu, E. (2013). Derivation of input/output relationships for the Bennett 6R linkages based on the method of decomposition, In: Proc. $2^{\text {nd }}$ Conf. on Mechanisms, Transmissions and Applications, Bilbao, pp. 225-231.

Bennett, G. T. (1905) The parallel motion of Sarrus and some allied mechanisms, Philosophy Magazine, 6th series, 9, 803810.

Cervantes-Sánchez, J.J., Medellín-Castillo, H.I., Rico-Martínez, J.M., González-Galván, E.J. (2009a). Some improvements on the exact kinematic synthesis of spherical 4R function generators. Mech. Mach. Theory, 44, 103-121.

Cervantes-Sánchez, J.J., Gracia, L., Rico-Martínez, J.M., Medellín-Castillo, H.I., González-Galván, E.J. (2009b). A novel and efficient kinematic synthesis approach of the spherical $4 \mathrm{R}$ function generator for five and six precision points. Mech. Mach. Theory, 44, 2020-2037.

Chebyshev, P. L. (1854). Théorie des mécanismes connus sous le nom de parallélogrammes. Mémoires Présentés à L'académie Impériale des Sciences de St.-Pétersbourg par Divers Savants, 7, 539-568.

Chebyshev, P. L. (1859). Sur les questions de minima qui se rattachent à la representation approximative des fonctions. Mémoires Présentés à L'académie Impériale des Sciences de St.-Pétersbourg, (6), Sciences Mathématiques et Physiques, 7, 199-291.

Erdman, A. and Sandor, G. N. (1997). Mechanism Design: Analysis and Synthesis, Vol. 1., Prentice Hall.

Farhang, K., Midha, A., Bajaj, A.K. 1988. Synthesis of harmonic motion generation linkages part-I, function generation. ASME J. Mech. Transm. Automat. Design, 110(1), 16-21.

Farhang K., Zargar Y.S. 1999. Design of spherical 4R mechanisms: function generation for the entire motion cycle. ASME J. Mech. Design, 121, 521-528.

Hartenberg, R.S., Denavit, J. (1964). Kinematic Synthesis of Linkages, McGraw-Hill, New York.

Maaroof, O. W. N., Dede, M. İ. C. (2013). A comparative study on application of decomposition method in function generation synthesis of over-constrained mechanisms. In: Petuya, V. et al. (Eds.), New Advances in Mechanisms, Transmissions and Applications, Mechanisms and Machine Science 17, Springer, 309-316.

Maaroof, O.W.N., Dede, M.İ.C. (2014) Kinematic synthesis of over-constrained double-spherical six-bar mechanism. Mech. Mach. Theory, DOI 10.1016/j.mechmachtheory.2013.10.013

Murray, A. P., McCarthy, J. M. (1995). A linkage map for spherical four position synthesis. ASME Tech. Conf. Boston, MA, 833-844.

Rao, M. A. V., Sandor, G. N., Kohli, D., Soni, A. H. (1973). Closed form synthesis of spatial function generating mechanism for the maximum number of precision points. J. Eng. Industry, 95, 725-736.

Remez, E. (1934). Sur le calcul effectif des polynomes d'approximation de Tschebyscheff. C. R. Acad. Sci., Paris, 199, 337 340.

Sarrus, P. T. (1853). Note sur la transformation des mouvements rectilignes alternatifs, en mouvements circulaires, et reciproquement. Academie des Sciences, 36, 1036-1038.

Selvi, Ö. (2012). Structural and Kinematic Synthesis of Overconstrained Mechanisms. PhD Thesis in Mechanical Engineering, İzmir Institute of Technology.

Suixian, Y., Hong, Y., Tian, G. Y. (2009) Optimal selection of precision points for function synthesis of spherical 4R linkage, Proc. Inst. Mech. Eng. C J. Mech. Eng. Sci., 223, 2183-2189.

Temes, G.C. (1967). Iterative Chebyshev approximation technique for network synthesis, IEEE Trans. Circuit Theory, 14(1), 31-37.

Zimmerman J. R. 1967. Four-precision synthesis of the spherical four-bar function generator. Mech. Mach. Theory, 2, 133139. 